\title{
Research on the Current Situation and Practice of the Integration of National Traditional Horse Racing Festival and Tourism
}

\author{
Yacheng Zhu ${ }^{1, *}$, Ping Zhu', Qing Zhang ${ }^{2}$ \\ ${ }^{1}$ College of Physical Education, Xizang Minzu University, Xianyang, Shaanxi, China \\ ${ }^{2}$ Department of Physical Education, Yangling Vocational and Technical College, Yangling, Shaanxi, China \\ *Corresponding Author: Yacheng Zhu
}

\begin{abstract}
:
National traditional sports events carry the task of developing the history and culture of ethnic minorities and are the soul of the development of tourism. National traditional sports events, cultural industries, and tourism industries interact and intersect each other, and the three are integrated and developed. The national traditional sports tourism industry is an important development direction for developing local culture, improving the tourism industry, promoting economic restructuring, and leveraging the local economy. The integration of national traditional sports and tourism is a new growth point for the national economy, which is not only conducive to the improvement of the local economic level, but also improves the development of the industrial structure, thereby promoting the sound development of the national traditional sports industry. In view of this, this research focuses on an in-depth and systematic study of the current situation and practice of the integration of national traditional horse racing festival and tourism, mainly discussing the following six aspects: The first is the analysis of the necessity of the integration of national traditional sports and tourism. The second is the analysis of the mechanism power, policy support and economic basis for the integration and development of national traditional horse racing and tourism. The third is the analysis of the development of Tibetan horse racing festival. The fourth is the analysis on the value and predicaments of the integrated development of Tibetan horse racing festival and tourism. The fifth is a case study of the practice of integrated development of Tibetan horse racing festival and tourism. The sixth is a strategic study on the integrated development of Tibetan horse racing festival and tourism. Main conclusions: National traditional horse racing festival is an important part of Chinese national tradition and national folk sports events. The development of national traditional horse racing festival is of great significance to boost rural revitalization, increase the income of farmers and herdsmen, cultivate new formats and models of sports and cultural tourism industries, meet the material and spiritual and cultural needs of the masses, and promote horse
\end{abstract}


racing culture. Put forward the development strategy of the integration of national traditional horse racing festival and tourism: constructing the coordinated development mechanism of national traditional horse racing festival and tourism. Give full play to the functions and values of traditional national horse racing culture, sports and entertainment. To advocate the development model of "national traditional horse racing festival + tourism", promote the coordinated development of horse breeding, equestrian sports, and cultural tourism, and form a new pattern of close connection, mutual benefit and win-win, and joint development of all links in the industrial chain. To promote the combination of national traditional horse racing festivals and special tourism. To develop theme and characteristic horseback riding tourism, select a batch of high-quality horseback riding tourism routes, and focus on creating national high-quality horseback riding tourism routes such as Silk Road tourism, Ancient Tea Horse Road ecological tourism, and grassland landscape tourism.

Keywords: Horse Racing Festival; Tibetan Horse Racing Festival; National Traditional Horse Racing Festival; Horse Racing Culture; National Traditional Sports; Sports Tourism; Festival Sports; Folk Sports; Sports and Travel Integration

\section{INTRODUCTION}

With the advent of mass fitness and mass tourism era, people's travel needs, lifestyles and leisure content have undergone tremendous changes. To adapt to the trend of rapid escalation of sports consumption and tourism consumption. Develop a tourism development model with "sports + tourism" products as the highlight. The two major industries of tourism and sports have formed a multi-level and multi-structure docking development model in the process of integration [1-3]. Nowadays, people pay more and more attention to health, and fitness exercises have gradually become a trend. Good body shaping makes many young people envy and actively exercise. On the one hand, it strengthens autoimmunity. On the other hand, it is pleasant to the body and mind. According to statistics, by 2020, the number of people in China who regularly participate in sports activities will be close to 500 million, and the number of people participating in leisure sports will be nearly 700 million [4]. The huge fitness crowd has brought great demand for sports leisure and sports fields, and a variety of leisure sports activities will become more and more popular leisure trends. The integration of sports and travel will open up another market for sports and leisure sports and bring a variety of sports forms to relax the body and mind and cultivate the mood while exercising [5-7].

The combination of national traditional sports resource development with festivals and tourism has become an emerging trend and an effective way to promote the development of national traditional sports. Many ethnic regions excavate and launch national traditional sports resources. Build it into an industrialized project. Cultivation has become a new bright spot for boosting tourism "blowout" growth. Promote the transformation of national cultural resource advantages into economic advantages. Provide industrial support for ethnic regions [8-10]. 
Traditional Tibetan sports activities have the characteristics of strong characteristics, rich connotation, large number and wide distribution. It is a treasure trove of resources worth exploring. Some national sports activities or traditional festivals have gained high popularity and influence after years of tourism promotion. Such as Tibet Nagqu Chaqing Qiangtang Horse Racing Culture and Art Festival, Dangxiong Dangjiren Horse Racing Festival, Gyangze Horse Racing Festival, Sichuan Litang Horse Racing Festival, Qinghai Yushu Horse Racing Club, Gannan Maqu Horse Racing Festival, Yunnan Shangri-La Horse Racing Festival, Diqing Tacheng Tibetan Horse Racing Festival and so on. The traditional sports of ethnic minorities have become the business cards of some places, such as horse racing and archery of Tibetans.

The integrated development of traditional national sports and tourism is the result of the multilevel, multi-directional, multi-path integration and borrowing of the two major industries. Integrated development can only fully penetrate, cross and complement in the fields of economy, culture, service, etc., to reduce costs, save resources, and refine the essence. In order to achieve a win-win situation in an increasingly fierce competitive environment [11-13]. The trend of integration and development of national traditional horse racing festivals and tourism has gradually emerged. The integration of Tibetan horse racing festival and tourism has become a development trend. At present, China's research on the integration and development of national traditional horse racing festival and tourism has confirmed that there is a natural connection between national traditional horse racing festival and tourism. The integration and development of national traditional horse racing festival and tourism is the main trend of the future development of national traditional horse racing festival. At the same time, it is also a new form of tourism development.

Through the study of traditional horse racing festival, the influence of holding national sports on the development of tourism in ethnic minority areas is discussed. The research results show that there is a mutually promoting relationship between the development of national sports and the development of tourism. Hosting national sports events can promote local infrastructure construction. Increase local tourism economic income. Improve the quality of tourism services. The development of sports events should break down the barriers of the respective management of sports, culture and tourism. Promote the interactive development of sports events and tourism with the idea of integrated development [14]. Judging from the historical development of horse racing, the government's attitude towards horse racing is very supportive. On this basis, to form an organic cycle of the horse racing ecological chain, the existence of collective horse racing activities must meet three conditions: The first is that the Tibetan people have this entertainment need. The second is that someone is willing and able to organize such activities. The third is that folk customs and folk festivals are a platform to showcase horse racing culture. It provides reasons for gathering and opportunities for performances for other forms of recreational activities (including commerce and trade). Coexist and develop with other forms of multiculturalism. In view of this, under the guarantee of the government's leadership and support, the organization will be improved. Strengthen the sports organization ability of village committees. Encourage the 


\section{Design Engineering}

holding of folklore sacrificial activities and folklore festivals. Establish a non-governmental sports tourism association or economic entity. Make various groups and groups continue to innovate this kind of horse racing that has been passed down from generation to generation along with the changes in their environment, their relationship with nature and historical conditions. At the same time, the Tibetan people themselves have a sense of identity and history. Firmness is the main attitude of a viable horse racing activity only if it is the folk. The horse racing, a folk folk sports activity, can be inherited [15].

The Yushu Horse Racing Festival is one of the most representative festivals in the Kham Tibetan area. It has profound historical and social cultural roots. It is a unique ethnic festival of Tibetans. "The 8th Kham Cultural Tourism Art Festival and Yushu Horse Racing Festival" is the first horse racing event that Yushu has recovered since the 2008 earthquake. This horse racing festival has inherited the traditional Tibetan culture. It also reflects the cultural status of Xinyushu's post-disaster reconstruction [16]. Through investigation, it is found that the development of horse racing on the March Street Ethnic Festival has promoted the development of local urbanization. It has promoted the development of the local economy and the overall development of the tourism industry and realized a networked society. At the same time, the horse racing program of the March Street Ethnic Festival has also been continuously improved. Help increase the visibility of local cultural festivals. Suggestions: First, to improve the competition organization and management system and organize diverse horse racing activities. The second is to strengthen the propaganda of the National Day and increase the popularity of the National Day. To strengthen its own management system, standardize entry regulations and requirements, and increase participation in programs. The third is to increase people's enthusiasm for participating in activities. To strengthen the construction of the venue to improve the standardization of the ethnic festival horse racing [17]. Starting from the origin, inheritance, development, and shortcomings of the "August 1st" International Horse Racing Festival in Litang County, we will use case analysis to explore how our country's ethnic minority areas use their distinctive cultural advantages as the cornerstone during the socialist market economy wave. Developing tourism as an opportunity, through integration and sublation, embark on a virtuous cycle of development that promotes economic development through folk festival tourism and promotes folk culture through economic development [18].

Through the analysis of the current situation of the horse racing industry in Gansu Province at home and abroad, the feasibility and development countermeasures of the horse racing industry in Gansu Province are proposed. To establish a reasonable horse racing industry structure, integrate other tourism projects related to horse racing, and increase publicity for the horse racing industry. To provide more platforms for economic growth in Gansu Province [19]. Sunan County is the center for the development of traditional sports in the Hexi region of Gansu Province. Since the Sunan County Horse Racing Conference was held, Sunan County has integrated sports and tourism industries based on its unique geographical environment and has broad development prospects. The following promotion strategies are proposed: First, in addition to horse racing 
events, the audience should be allowed to participate in other entertainment activities, so that the audience can experience the happiness of the event. Second, increase venue competitions, develop the horse industry based on local favorable conditions, and continuously improve the level of riders, making horse racing more enjoyable and competitive. Third, through training and exchanges and other methods to train relevant personnel of event planning, or go out to visit and exchange, continuously improve the planning level of management personnel, make the holding of the horse race more perfect, various measures more detailed, and improve the level of holding the event. Fourth, the government should also improve other surrounding entertainment facilities in addition to horse racing activities, continue to meet the needs of tourists who come to visit, and continue to meet the various conditions of the event [20]. Maqu Horse Racing Festival is a part of Gesar culture, and it is also a concentrated expression of local cultural customs and historical aesthetics. In recent years, under the guidance of the government, the development of horse racing festivals tends to be standardized and systematic. The annual horse racing has contributed to the development of local tourism, economy and culture. Created a more beautiful Maqu and the "Hometown of Horse Racing in China". It proposed a path to deeply explore the regional culture of Maqu, spread the culture of Maqu Gesar horse racing, and create a "happy and beautiful new Maqu" [21].

There are relatively few studies on the integration and development of national traditional horse racing festival and tourism abroad. However, sports events or horse racing activities have richer research on tourism. The author tries to use the "SOAR" method to study the positive aspects of tourism planning, in order to provide guidance and implementation strategies for the development of tourism. In this research, first, determine the advantages and opportunities in the development of urban tourism. Then, consider the main goal of tourism development in the region. Finally, specific strategies for the development of urban tourism are proposed [22]. Using three methods: bibliometric analysis, content analysis and quantitative system evaluation analysis, an objective and systematic review of western adventure tourism research literature is carried out to discover the theoretical basis and key themes of this field. The first is the adventure travel experience. The second is destination planning and development. The third is adventure tourism operators. Adventure tourism has the knowledge tradition of many disciplines, such as social psychology of sports and leisure. And pointed out that in the study of non-western tourists in their own geographical environment or non-western tourists in the western geographical environment, they are under-represented [23].

Compared with many other forms of tourism, the development of outdoor sports tourism is more closely related to the natural environment. The natural environment, sports activities, and the motivations of participants interact with each other to form the experience of sports tourism. The safety and security of tourists has proven to be an important factor in the tourist experience. Moreover, compared with non-sport tourists, sports tourists seem to be more sensitive to safety issues [24]. It is believed that sports events have contributed to the development of tourist destinations through direct participation and destination image building. But in terms of its 
contribution to the development of the destination network, people don't know enough about sports events. Overall, sports events can become a mechanism. Destinations can develop products and services through this mechanism, and use the resources and capabilities of multiple companies to contribute to destination development [25].

The research introduces the historical and religious aspects of traditional sports competitions in Mongolia in the north of South Siberia and the Buryat Mongolian in the northeast. Traditional sports have been closely linked with shamanistic rituals throughout history. This research puts forward different opinions on the functions of traditional sports competitions on Buryat shaman rituals. National traditional sports competitions are still an indispensable part of religious rituals. It is believed that national traditional sports competitions play an important role in religious ceremonies, which are designed to deceive and please the spirits and gods of Buryats in order to obtain what they need for survival [26].

The Autonomous Republic of Kazakhstan has long been a center of horse breeding. In the north of the country, there are large tracts of grassland, and a large number of wild horses have been acquired and accepted in history. In the early stages of horse domestication in the 4th to 5th millennium BC, this alliance of the country played an important role. At the International Conference held in Petropavlovsk in June 1995, the title of the conference was "Early Horseback Riders in the Eurasian Steppe". The Soviet government strongly supports horse breeding. Therefore, it is still possible for modern people to celebrate Kazakhstan's long tradition of different kinds of horse racing and horse racing. In years of hard field work, compiled knowledge about traditional methods of training horses, judging horses and traditional methods of treating horses. It can be seen from the literature on this particular subject that the training methods of Kazakhs in Central Asia and other races seem to have a common origin [27].

The research uses Analytic Hierarchy Process (AHP) to analyze several business plans required for tourism and horse racing activities, and rank the projects. As a result, the tourism activity game that developed tourism products based on horse racing was evaluated as the most necessary item. Among them, the horse racing tourism score was 0.238 , the horse racing tourism infrastructure construction score was 0.186 , the horse racing tourism policy support score was 0.182 , and the PR and marketing scores were 0173 . The price of different tourism products and the diversification of sales channels, the horse racing tourism development project scored 0.118 . At the end of the year, it scored 0.103 and was rated as a priority development project. Avoid simple horse racing event development and combine horse racing with sports marketing. Easy, interesting and diversified betting forms, interesting public relations and targeted marketing activities, so that product development requires the development of horse races in different regions. Strengthen Internet marketing and social marketing to improve the communication and influence of horse racing events. In addition, by changing the way of horse racing, such as strengthening the construction of tourism infrastructure and tourism projects, broadening the sales channels of horse racing souvenirs, and building a horse racing theme park, the focus of horse racing tourism activity planning has been proposed [28]. 
To sum up, there have been preliminary studies on the integration and development of national traditional horse racing festival and tourism at home and abroad, but they are not yet complete. There is also a lack of practical research on the integration of Tibetan horse racing festivals and tourism, and there is insufficient discussion on related issues. In view of this, this research mainly conducts in-depth research on the current situation and practice of the integration of ethnic traditional horse racing festivals and tourism. This research attempts to answer the following six questions: The first question is the analysis of the necessity of the integration of traditional national sports and tourism, which is the logical starting point of this research. The second question is the mechanism power, policy support and economic basis analysis of the integrated development of national traditional horse racing festival and tourism, which are the supporting points of this research. The third question is an analysis of the development of Tibetan horse racing festivals, and a comprehensive understanding of the development status of Tibetan horse racing festivals and the development of major Tibetan horse racing festivals. This is the foothold of this research. The fourth question is the analysis of the value and dilemma of the integrated development of Tibetan horse racing festival and tourism, which is the key to the integrated development of this research. The fifth question is the case analysis of the practice of integrated development of Tibetan horse racing festival and tourism, mainly based on the Nagqu Qiangtang Chaqing Horse Racing Festival in Tibet Autonomous Region, Shangri-La Horse Racing Festival in Yunnan Province, Maqu “Gesar" Horse Racing Festival in Gansu Province, Sichuan Province Tang Horse Racing Festival and Yushu Horse Racing Festival in Qinghai Province and typical cases of tourism integrated development are analyzed, which are the main carriers of this research. The sixth question is the strategic study of the integrated development of Tibetan horse racing festival and tourism. This is the purpose and destination of this research.

\section{METHODS}

Mainly use literature data method, historical research method, logical analysis method and case analysis method to study the current situation and practice of the integration of national traditional horse racing festival and tourism. Chinese literatures are mainly searched by CNKI, and the search date is November 6, 2020. Using the title of "national traditional horse racing festival" and including "tourism" for retrieval, a total of 20 related literatures were retrieved. See Table I for details. It also reads, summarizes and sorts out the retrieved literatures in detail, extracts relevant information, and provides reference materials for literatures review. Foreign language literatures were retrieved using foreign language databases, and the retrieval date was November 6, 2020. Enter keywords such as "tourism", "national traditional sports events", and "horse racing" in the subject column of the database, mainly using Web of Science database, EI Village database, Scopus database, Wiley Online Library database and SpringLink database to search. 


\section{TABLE I. A list of research literatures on the integration and development of national traditional horse racing festival and tourism in Chinese periodicals}

\begin{tabular}{|c|c|c|c|c|c|c|c|}
\hline $\begin{array}{c}\text { Serial } \\
\text { number }\end{array}$ & First author & Title & Journal Title & Year & Volume & Issue & $\begin{array}{c}\text { Page } \\
\text { Number }\end{array}$ \\
\hline 1 & Yao Li & $\begin{array}{l}\text { A Brief Talk on the Impact of the Horse Race in Dali } \\
\text { Sanyue Street Ethnic Festival on the Local Economy }\end{array}$ & $\begin{array}{l}\text { Sports Supplies } \\
\text { and Technology }\end{array}$ & 2020 & & 10 & $84-85$ \\
\hline 2 & Ju Zhao & $\begin{array}{l}\text { SWOT Analysis on the Development of Tibetan Horse } \\
\text { Racing Festival under the Background of the } \\
\text { Construction of Beautiful Tibet }\end{array}$ & Wushu Research & 2020 & 5 & 03 & $123-128$ \\
\hline 3 & He Zhang & $\begin{array}{l}\text { Investigation on the development status of Gannan } \\
\text { Maqu "Gesar Jockey Club" }\end{array}$ & $\begin{array}{c}\text { Cultural and } \\
\text { educational } \\
\text { materials }\end{array}$ & 2020 & & 03 & $97-99$ \\
\hline 4 & $\begin{array}{l}\text { Qiangping } \\
\text { Ye }\end{array}$ & $\begin{array}{l}\text { Litang: The Pearl of the Grassland and the Hometown } \\
\text { of Equestrianism }\end{array}$ & Business manager & 2019 & & 10 & $104-107$ \\
\hline 5 & Zhen Shi & $\begin{array}{c}\text { Research on the Status Quo and Development of } \\
\text { Tibetan Traditional Sports Rural Horse Racing_-A } \\
\text { Case Study of Horse Racing in Sexiong Township, } \\
\text { Nagqu }\end{array}$ & Western leather & 2019 & 41 & 18 & 100 \\
\hline 6 & $\begin{array}{c}\text { Luo sang ze } \\
\text { ren }\end{array}$ & $\begin{array}{l}\text { On the Integration of Tourism and the Chaqing Horse } \\
\text { Racing Festival in the Qiangtang of Nagqu, Tibet }\end{array}$ & $\begin{array}{l}\text { Journal of Tibet } \\
\text { University } \\
\text { (Social Science } \\
\text { Edition) }\end{array}$ & 2019 & 34 & 03 & $55-59$ \\
\hline 7 & Wei Lv & $\begin{array}{c}\text { A Study on the Current Situation of Jockey Clubs in } \\
\text { Hexi Region of Gansu Province--Taking Sunan } \\
\text { County as an Example }\end{array}$ & Wushu Research & 2019 & 4 & 05 & $121-123$ \\
\hline 8 & Xiyan Li & $\begin{array}{c}\text { Research on the Development of Tibet Nagqu Chaqing } \\
\text { Horse Race Tourism }\end{array}$ & $\begin{array}{c}\text { Hubei Sports } \\
\text { Technology }\end{array}$ & 2018 & 37 & 07 & $591-593$ \\
\hline 9 & $\begin{array}{l}\text { Jianzhi } \\
\text { Zheng }\end{array}$ & $\begin{array}{c}\text { The Tourism Value Analysis of Traditional Horse } \\
\text { Racing of Shui Nationality in Sandu County of } \\
\text { Southern Guizhou }\end{array}$ & Sports Boutique & 2018 & 37 & 06 & $53-54$ \\
\hline 10 & $\begin{array}{l}\text { Zhixing } \\
\text { Zhao }\end{array}$ & $\begin{array}{l}\text { The Role of Ethnic Minority Traditional Sports in the } \\
\text { Tourism Industry--Taking the Horse Race on March } \\
\text { Street of Bai Nationality in Dali as an Example }\end{array}$ & $\begin{array}{l}\text { Anhui Sports } \\
\text { Technology }\end{array}$ & 2016 & 37 & 06 & $18-20$ \\
\hline 11 & $\begin{array}{l}\text { Zhaolong } \\
\text { Zhang }\end{array}$ & $\begin{array}{l}\text { Research on the Interactive Development of } \\
\text { Traditional Sports Festivals and Tourism }\end{array}$ & $\begin{array}{c}\text { Journal of Ezhou } \\
\text { University }\end{array}$ & 2016 & 23 & 06 & $92-94$ \\
\hline
\end{tabular}




\begin{tabular}{|c|c|c|c|c|c|c|c|}
\hline 12 & Xiyan He & $\begin{array}{c}\text { Field Investigation of Qinghai Yushu Jockey Club--A } \\
\text { case study of "The 8th Kham Cultural Tourism Art } \\
\text { Festival and Yushu Jockey Club" }\end{array}$ & $\begin{array}{l}\text { Journal of } \\
\text { Nationality } \\
\text { Normal College } \\
\text { of Qinghai } \\
\text { Normal } \\
\text { University }\end{array}$ & 2015 & 26 & 02 & $7-13$ \\
\hline 13 & $\begin{array}{l}\text { Tianliang } \\
\text { Song }\end{array}$ & $\begin{array}{c}\text { Analysis on the Development of China Maqu "Gesar" } \\
\text { Jockey Club and Related Industries }\end{array}$ & $\begin{array}{c}\text { Journal of Gansu } \\
\text { Normal } \\
\text { University }\end{array}$ & 2015 & 20 & 03 & $139-142$ \\
\hline 14 & Gang Zhou & $\begin{array}{l}\text { Feasibility Study on the Development of Horse Racing } \\
\text { Industry in Gansu Province }\end{array}$ & $\begin{array}{l}\text { Sports Supplies } \\
\text { and Technology }\end{array}$ & 2015 & & 08 & $8-9$ \\
\hline 15 & Jinbin Liu & $\begin{array}{l}\text { A Historical Analysis of the Tibetan Horse Race in } \\
\text { Kangding }\end{array}$ & $\begin{array}{l}\text { Fighting (Sports } \\
\text { Forum) }\end{array}$ & 2014 & 6 & 02 & $83-86$ \\
\hline 16 & Guoyu Chen & $\begin{array}{c}\text { The Protection and Inheritance of the "Duanjie" Horse } \\
\text { Racing Culture of Guizhou Shui People from the } \\
\text { Perspective of Intangible Cultural Heritage--Taking } \\
\text { Tangzhou Village, Tangzhou Township, Sandu Shui } \\
\text { Autonomous County, Guizhou Province as an } \\
\text { Example }\end{array}$ & \begin{tabular}{|} 
Journal of \\
Guizhou Normal \\
University
\end{tabular} & 2012 & 28 & 06 & $49-52$ \\
\hline 17 & Peijie Zhou & $\begin{array}{c}\text { Analysis of the Current Situation of China·Maqu } \\
\text { Gesar Race Tournament and Development } \\
\text { Countermeasures }\end{array}$ & $\begin{array}{c}\text { Journal of Gansu } \\
\text { Lianhe University } \\
\text { (Natural Science } \\
\text { Edition) }\end{array}$ & 2008 & & 04 & $110-112$ \\
\hline 18 & Xuejiao Xie & $\begin{array}{l}\text { A Preliminary Study on the Tourism Management of } \\
\text { Ethnic Minority Folk Festivals--Taking "August 1st } \\
\text { International Horse Racing Festival" in Litang County } \\
\text { as an example }\end{array}$ & $\begin{array}{l}\text { Legal system and } \\
\text { society }\end{array}$ & 2008 & & 08 & 213 \\
\hline 19 & $\begin{array}{l}\text { Dongmei } \\
\text { Chen }\end{array}$ & $\begin{array}{l}\text { Nagqu Horse Racing Festival-a grand event of } \\
\text { grassland culture and tourism economy }\end{array}$ & Tibet Tourism & 2007 & & 05 & $36-45$ \\
\hline 20 & Min Liang & $\begin{array}{l}\text { A Preliminary Study on the Model of Combining } \\
\text { Traditional Festivals with Tourism Economy in Ethnic } \\
\text { Minority Areas--Taking “August 1st" International } \\
\text { Horse Racing Festival in Litang County as an Example }\end{array}$ & \begin{tabular}{|c|} 
Journal of Hubei \\
University for \\
Nationalities \\
(Philosophy and \\
Social Sciences \\
Edition)
\end{tabular} & 2007 & & 01 & $37-41$ \\
\hline
\end{tabular}

\section{RESULT ANALYSIS}

2.1. The Analysis of the Necessity of the Integration of National Traditional Sports and Tourism

As an important part of the excellent traditional culture of the Chinese nation, traditional national sports have distinct regional and national characteristics, and have multiple functions of 
fitness, viewing, entertainment and participation. The integration of tourism has become a major trend in the development of global tourism. The new bright spots under the country are of great significance to the sustainable development of the national traditional sports industry, the innovative development of national traditional sports projects, the promotion of traditional culture and the strengthening of cultural confidence. The necessity of the integrated development of national traditional sports and tourism is mainly reflected in the following three aspects: First, strengthen cultural self-confidence and enhance national identity. Incorporating excellent national traditional sports into the sports tourism industry will help establish a benign interactive relationship between national traditional sports and the economy, realize the organic integration of recreational sports and economic development, and thus build cultural consensus and strengthen cultural confidence. Second, make full use of resources to promote integration and symbiosis. Both the sports industry and the tourism industry belong to the tertiary industry and have similar characteristics. They are the products of a certain stage of economic development. They have strong industrial relevance. The integrated development of national traditional sports and tourism is necessary and feasible. The relevance of social functions such as leisure and entertainment, physical fitness, self-cultivation, and social communication provide profit space and platform carriers for the upgrading of tourism industry and the promotion of national traditional sports. Third, update the development thinking to meet the upgrading needs. The characteristics of participation, interest, mystery and adventurousness of national traditional sports tourism actually cater to the direction of future tourism. With the upgrading of tourism taste, the emphasis on health preservation, active participation and active experience have become the dominant demand, and the tourism market calls for in-depth experience tourism products [29$30]$.

2.2 The Analysis of the Mechanism Power, Policy Support and Economic Basis for the Integration and Development of National Traditional Horse Racing Festival and Tourism

1) The mechanism motive force of the integrated development of national traditional horse racing festival and tourism

National traditional horse racing festival is a part of sports events, and sports events are an important part of the sports industry. Therefore, analyzing the internal mechanism of the integrated development of the sports industry and the cultural tourism industry is the prerequisite for analyzing the internal mechanism of the integrated development of national traditional horse racing festivals and tourism. The internal mechanism of the integrated development of the sports industry and the cultural tourism industry is based on the interconnection of elements of the sports industry and the cultural tourism industry. That is, the flow of people, logistics, information and capital flows among the three industries. Jointly promote the recombination of sports assets (event assets, venue assets, facility assets, etc.), tourism assets (natural assets, geographical assets, human assets, etc.) and cultural assets. And then produce innovative industrial formats. As shown in Fig 1. 


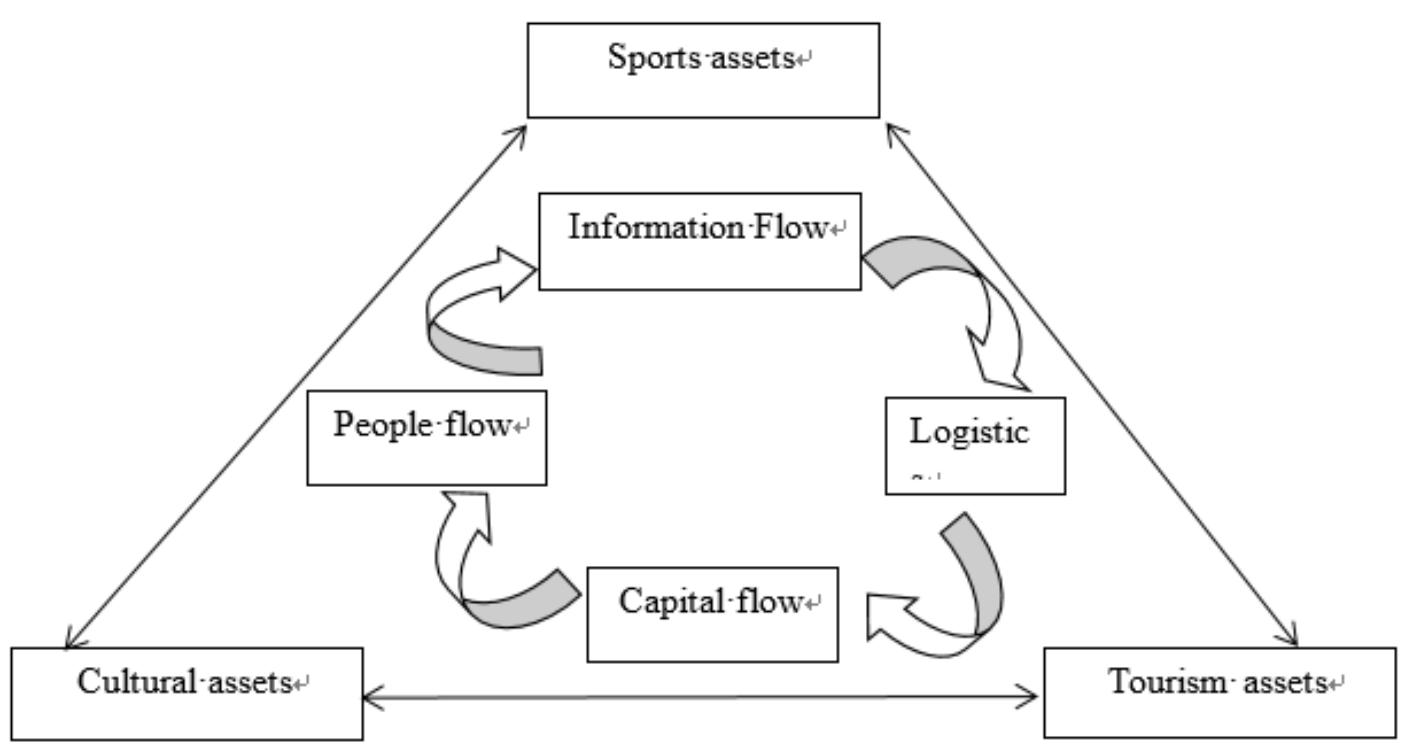

Fig 1. The internal mechanism of the integrated development of sports industry and cultural tourism industry

The internal mechanism of the integration of the sports industry and the cultural and tourism industry is the basic condition for industrial integration, but it will not make the three major industries naturally move towards the road of integrated development. The integrated development of the sports industry and the cultural and tourism industry needs to be stimulated by external conditions, including policy support related to the development of the sports industry, continuous innovation of science and technology, competition and cooperation between enterprises, and diversified market demand. As shown in Fig 2.

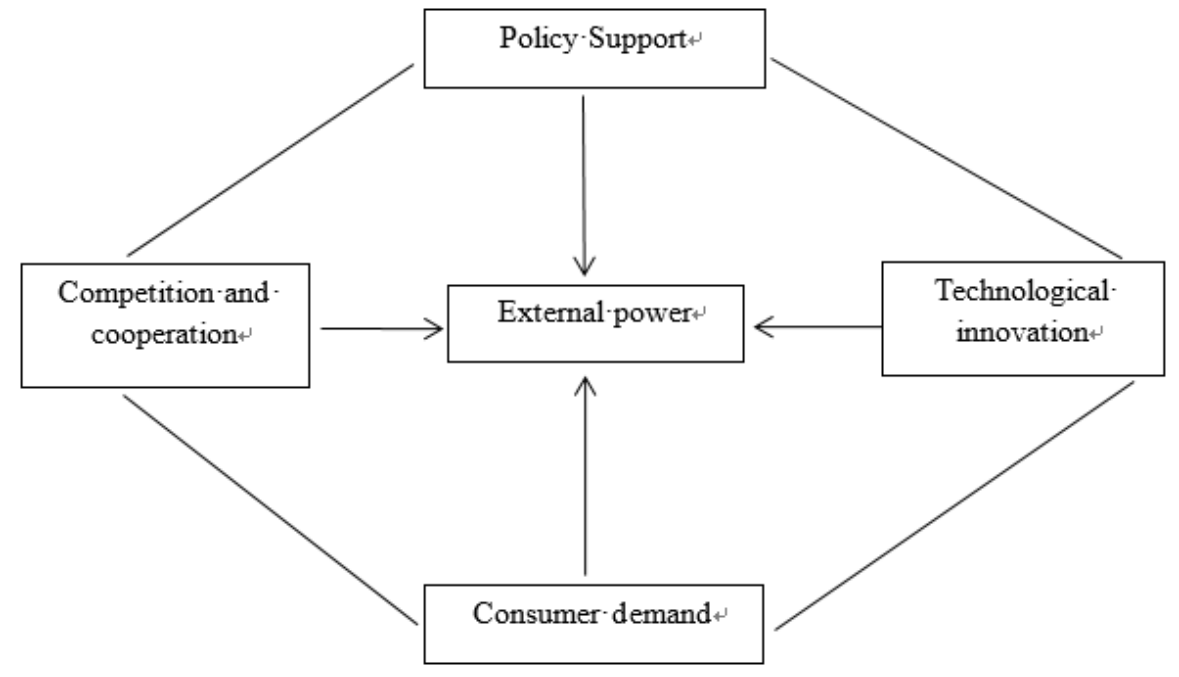

Fig 2: External driving force for the integrated development of sports industry and cultural tourism industry 
2) Policy support for the integration and development of national traditional horse racing festival and tourism

The integration and development of national traditional horse racing festival and tourism has received strong support from national and local governments at all levels, especially in ethnic areas where horse racing is relatively well developed. The relevant policies are detailed in Table II. The Tibetan Horse Racing Festival is not only a traditional festival, but also an important part of national traditional sports. It is also a combination of the ancient tea-horse road culture and the life culture of the people in Tibetan areas. Because culture is the root of a nation, the soul of a nation, and the source of a nation. Establishing self-confidence in Tibetan culture is an inherent requirement for the development of Tibetan horse racing festivals and is of great value to the development of local tourism. At the same time, holding Tibetan horse racing festivals can satisfy the Tibetan people's yearning for a better sports life.

\section{TABLE II. A list of policies concerning the integrated development of Tibetan horse racing festivals and tourism in recent years}

\begin{tabular}{|c|c|c|}
\hline Issue time & Policy name & Related policy description \\
\hline $2020-09-18$ & $\begin{array}{l}\text { China Horse Industry Development } \\
\text { Plan (2020-2025) }\end{array}$ & $\begin{array}{l}\text { Establish a coordinated development mechanism for national traditional } \\
\text { horse racing festivals and tourism. Give full play to the functions and values } \\
\text { of traditional ethnic horse racing festival culture, sports and entertainment, } \\
\text { and advocate the development model of "traditional ethnic horse racing } \\
\text { festival + tourism". Promote the combination of ethnic traditional horse } \\
\text { racing festivals and special tourism. Develop theme and characteristic } \\
\text { horseback riding tourism, select a batch of high-quality horseback riding } \\
\text { tourism routes, and focus on creating national high-quality horseback } \\
\text { riding tourism routes such as Silk Road tourism, Ancient Tea Horse Road } \\
\text { ecological tourism, and grassland landscape tourism. }\end{array}$ \\
\hline $2020-07-30$ & $\begin{array}{l}\text { Implementation Opinions of the } \\
\text { Tibetan Government on Speeding up } \\
\text { the Construction of a Strong Sports } \\
\text { District }\end{array}$ & $\begin{array}{l}\text { Promote integrated development and implement the "Sports }+ \text { " strategy to } \\
\text { promote the integrated development of sports and tourism, health and } \\
\text { wellness, culture, education, technology, agriculture and animal husbandry, } \\
\text { poverty alleviation, media, finance, exhibitions, and real estate. Optimize } \\
\text { the sports consumption environment, strengthen the supervision of the } \\
\text { sports market, stimulate sports consumption demand, and promote the } \\
\text { continuous upgrading of sports consumption. }\end{array}$ \\
\hline
\end{tabular}




\begin{tabular}{|c|c|c|}
\hline 2020-05-17 & $\begin{array}{l}\text { Guiding Opinions of the Chinese } \\
\text { Government on Promoting the } \\
\text { Development of the West in the New } \\
\text { Era and Forming a New Pattern }\end{array}$ & $\begin{array}{l}\text { Give full play to the comparative advantages of the western region, promote } \\
\text { the development of qualified industrial clusters, take greater steps in } \\
\text { cultivating new kinetic energy and the transformation and upgrading of } \\
\text { traditional kinetic energy, and promote the wide application and deep } \\
\text { integration of information technology in traditional industries to build a } \\
\text { competitive edge Modern industrial system. Promote the development of } \\
\text { new business formats such as "Internet + education", "Internet + medical } \\
\text { treatment", and "Internet + tourism", promote network acceleration and fee } \\
\text { reduction, and accelerate the development of cross-border e-commerce. } \\
\text { Support the western region to leverage its advantages in ecology, ethnic } \\
\text { folklore, and border scenery, deepen international cooperation in tourism } \\
\text { resource opening, information sharing, industry supervision, public } \\
\text { services, tourism safety, and standardized services, and improve the level } \\
\text { of tourism services. }\end{array}$ \\
\hline 2019-01-24 & $\begin{array}{l}\text { Notice on Issuing the } \\
\text { Implementation Plan for Improving } \\
\text { the Consumption Promotion System } \\
\text { and Mechanism (2018-2020) }\end{array}$ & $\begin{array}{l}\text { Use time nodes such as "National Fitness Day" and traditional national } \\
\text { holidays to organize and carry out national fitness activities such as horse } \\
\text { racing and Guozhuang dance to create a national fitness activity brand. }\end{array}$ \\
\hline $2018-07-30$ & $\begin{array}{l}\text { Implementation Opinions of the } \\
\text { Tibetan Government on Accelerating } \\
\text { the Development of Fitness and } \\
\text { Leisure Industry }\end{array}$ & $\begin{array}{l}\text { Encourage localities to combine agricultural and animal husbandry } \\
\text { culture, festivals, and tourism resources to vigorously develop the } \\
\text { traditional sports industry of ethnic minorities, regard traditional ethnic } \\
\text { minority sports as an important force in promoting the economic and } \\
\text { social development of ethnic regions, and strengthen the development of } \\
\text { ethnic minority traditional sports resources and industrial support. } \\
\text { Promote the deep integration of folk sports activities, ethnic sports } \\
\text { tourism, economic exchanges, convention and exhibition activities, and } \\
\text { ethnic art. }\end{array}$ \\
\hline 2018-03-16 & $\begin{array}{l}\text { Guiding Opinions on Further } \\
\text { Strengthening the Work of Minority } \\
\text { Traditional Sports }\end{array}$ & $\begin{array}{l}\text { Increase the development of national sports resources and industrial } \\
\text { support, and promote the integrated development of national sports, } \\
\text { tourism, and culture. Strengthen the traditional sports exchanges of all } \\
\text { ethnic groups, actively "go out", and promote the national sports culture } \\
\text { along the "One Belt and One Road". }\end{array}$ \\
\hline 2017-08-06 & $\begin{array}{l}\text { Tibet Government's "Thirteenth } \\
\text { Five-Year" Tourism Development } \\
\text { Plan }\end{array}$ & $\begin{array}{l}\text { By the end of the "13th Five-Year Plan", the tourism industry will be } \\
\text { cultivated as the leading industry of the national economy, and a } \\
\text { relatively complete tourism industry system will be formed. It will play an } \\
\text { important role in changing the development mode, adjusting the structure, } \\
\text { maintaining growth, promoting employment and benefiting people's } \\
\text { livelihood. }\end{array}$ \\
\hline 2017-07-04 & $\begin{array}{l}\text { The Tibetan Government's Sports } \\
\text { Development Plan During the 13th } \\
\text { Five-Year Plan }\end{array}$ & $\begin{array}{l}\text { Build competitive equestrianism into a fist event with Tibetan } \\
\text { characteristics and comparative advantages. }\end{array}$ \\
\hline
\end{tabular}




\begin{tabular}{|c|c|c|}
\hline 2016-11-07 & $\begin{array}{l}\text { Sports Law of the People's Republic } \\
\text { of China (Amended in 2016) }\end{array}$ & $\begin{array}{l}\text { Chapter I Article 6: The state supports the development of sports } \\
\text { undertakings in minority areas and cultivates minority sports talents. } \\
\text { Chapter II Article 15: The state encourages and supports the exploration, } \\
\text { arrangement and improvement of ethnic and folk traditional sports. } \\
\text { Chapter III Article 33: The principle of fair competition shall be } \\
\text { implemented in sports competitions. }\end{array}$ \\
\hline 2016-10-25 & $\begin{array}{l}\text { Guiding Opinions on Accelerating } \\
\text { the Development of Fitness and } \\
\text { Leisure Industry }\end{array}$ & Promote the healthy development of equestrian and other fashion sports. \\
\hline $2015-08-08$ & $\begin{array}{l}\text { Implementation Opinions on } \\
\text { Accelerating the Development of the } \\
\text { Sports Industry and Promoting } \\
\text { Sports Consumption }\end{array}$ & $\begin{array}{l}\text { Use important festival nodes such as Gyangze Dama Festival and } \\
\text { Wangguo Festival to develop traditional national sports performances. }\end{array}$ \\
\hline
\end{tabular}

Note: The source of information is the official website of the Chinese government.

3) The economic foundation for the integration and development of national traditional horse racing festival and tourism

The economic foundation for the development of sports industry and sports tourism industry is the condition for the integration and development of national traditional horse racing festival and tourism. To analyze the economic basis of the integration and development of national traditional horse racing festivals and tourism, we must first understand the status quo of the development of sports industry and sports tourism industry. At present, China's sports industry and sports tourism industry are showing two-way positive growth. According to the data released by the National Bureau of Statistics of China: In 2018, the total scale (total output) of the national sports industry was 2657.9 billion yuan, with an added value of 1007.8 billion yuan, and the added value of the sports industry accounted for 1.1\% of GDP [31]. In 2018, the market size of China's sports tourism industry was 260.5 billion yuan [32]. In 2018, the added value of tourism and related industries nationwide was $4,147.8$ billion yuan, accounting for $4.51 \%$ of the gross domestic product (GDP), an increase of 0.05 percentage points from the previous year [33]. In 2019 , the total scale (total output) of the national sports industry was 2657.9 billion yuan, with an added value of 1007.8 billion yuan, and the added value of the sports industry accounted for $1.1 \%$ of the GDP [34]. The statistics of China's sports industry scale and value added from 2012 to 2018 and the statistics of China's sports tourism industry market scale from 2013 to 2018 are shown in Fig 3 and Fig 4. The added value of national tourism and related industries in 2018 and the added value of China's sports industry and related industries in 2019 are detailed in Tables III and IV. From the relevant data in Fig 3 and Fig 4, Table I and Table II, it can be seen that China's sports industry and sports tourism industry have shown relatively rapid growth, which has laid a good economic foundation for the integration and development of national traditional 


\section{Design Engineering}

horse racing festivals and tourism.

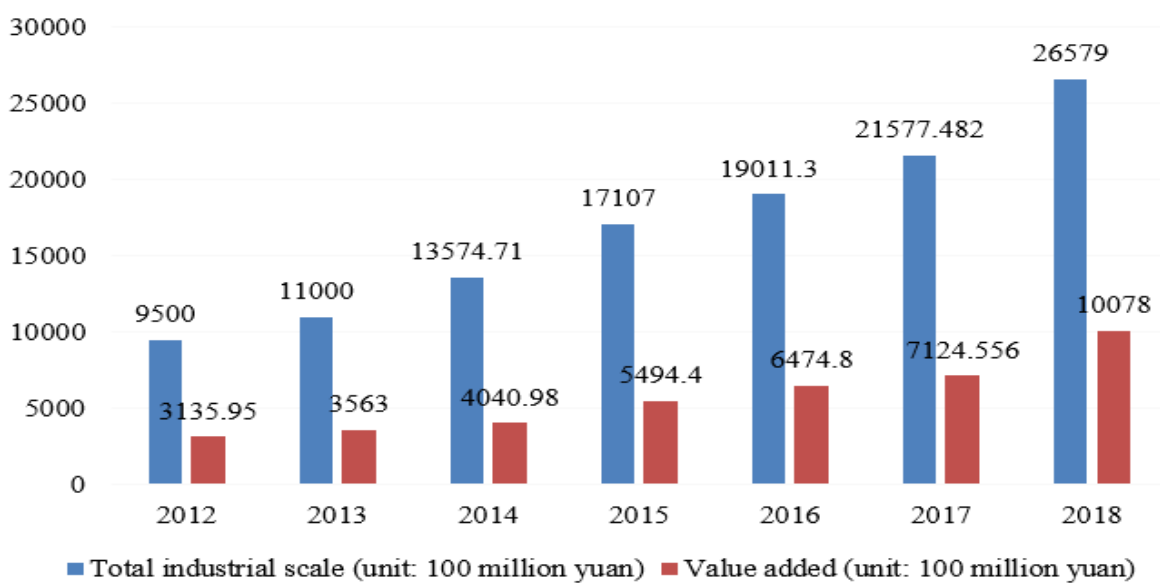

Fig 3. Statistics on the scale and added value of China's sports industry from 2012 to 2018

Market size (unit: 100 million yuan)

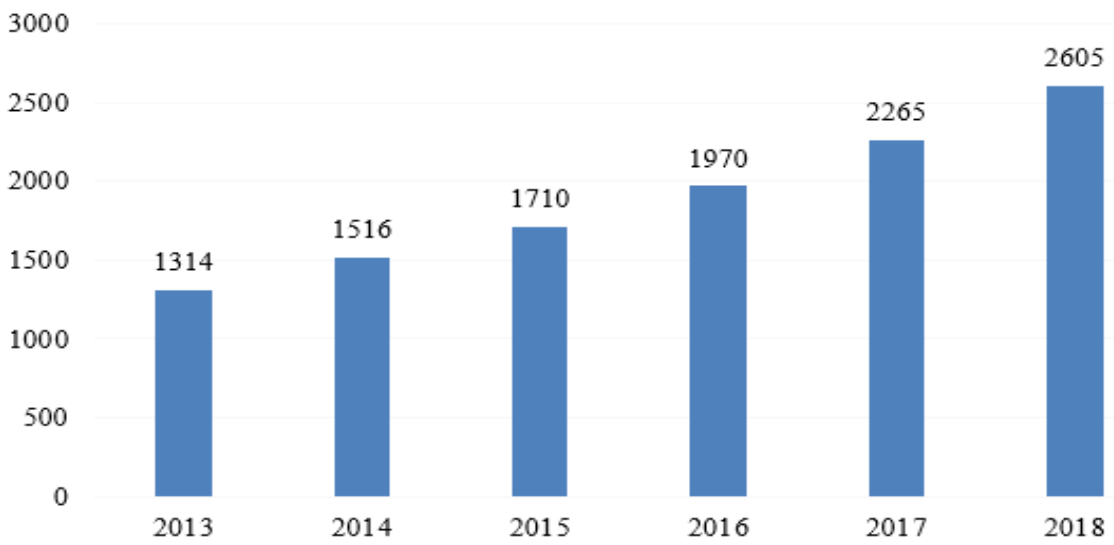

Fig 4. Statistics of China's sports tourism industry market scale from 2013 to 2018

TABLE III. The added value of China's tourism and related industries in 2018

\begin{tabular}{|l|c|c|c|}
\hline Category Name & $\begin{array}{c}\text { Value added (unit: 100 } \\
\text { million yuan) }\end{array}$ & Composition (Unit: \%) & Proportion of GDP (unit: \%) \\
\hline
\end{tabular}




\section{Design Engineering}

ISSN: 0011-9342

Issue: 1 | Pages: 75 - 114

\begin{tabular}{|c|c|c|c|}
\hline Tourism and related industries & 41478 & 100.0 & 4.51 \\
\hline Tourism & 37501 & 26.9 & 1.08 \\
\hline Travel & 11173 & 7.9 & 0.35 \\
\hline Tourist accommodation & 3262 & 13.6 & 0.62 \\
\hline Tourism Catering & 5659 & 4.8 & 0.22 \\
\hline Tourist excursion & 2011 & 31.4 & 0.41 \\
\hline Travel shopping & 13005 & 4.0 & 0.18 \\
\hline Tourism and entertainment & 1667 & 1.7 & \\
\hline Comprehensive Tourism & 723 & & \\
\hline Service & 3976 & 9.6 & 0.43 \\
\hline Tourism related industries & & & \\
\hline
\end{tabular}

Note: The data comes from the National Bureau of Statistics of China. If the total of the data sub-items is different from the total amount, it is due to the rounding error of the value.

TABLE IV. The added value of China's sports industry and related industries in 2019

\begin{tabular}{|c|c|c|c|c|}
\hline \multirow[t]{2}{*}{ Category Name } & \multicolumn{2}{|c|}{$\begin{array}{c}\text { Total amount (unit: } 100 \\
\text { million yuan) }\end{array}$} & \multicolumn{2}{|c|}{ Structure (unit: \%) } \\
\hline & Total output & Value Added & Total output & Value Added \\
\hline Sports industry & 26579 & 10078 & 100.0 & 100.0 \\
\hline Sports Service Industry & 12732 & 6530 & 47.9 & 64.8 \\
\hline Sports management activities & 747 & 390 & 2.8 & 3.9 \\
\hline Sports competition performance & 292 & 103 & 1.1 & 1.0 \\
\hline Sports fitness and leisure activities & 1028 & 477 & 3.9 & 4.7 \\
\hline Sports venue and facility management & 2632 & 855 & 9.9 & 8.5 \\
\hline $\begin{array}{l}\text { Sports brokerage and agency, advertising and exhibition, performance and } \\
\text { design services }\end{array}$ & 317 & 106 & 1.2 & 1.1 \\
\hline Physical Education and Training & 1722 & 1425 & 6.5 & 14.1 \\
\hline
\end{tabular}




\begin{tabular}{|c|c|c|c|c|}
\hline Sports Media and Information Service & 500 & 230 & 1.9 & 2.3 \\
\hline Sports goods and related products sales, rental and trade agency & 4116 & 2327 & 15.5 & 23.1 \\
\hline Other sports services & 1377 & 616 & 5.2 & 6.1 \\
\hline Sports goods and related products manufacturing & 13201 & 3399 & 49.7 & 33.7 \\
\hline Sports facilities construction & 646 & 150 & 2.4 & 1.5 \\
\hline
\end{tabular}

Note: The data comes from the National Bureau of Statistics of China. If the total of the data sub-items is different from the total amount, it is due to the rounding error of the value.

2.3 The Analysis of the Development of Tibetan Horse Racing Festival

Horse racing has always been one of the favorite sports of Chinese Tibetans. There are more than 3.87 million Tibetan compatriots in China. Except for more than 1.78 million people living in the Tibet Autonomous Region, the remaining Tibetans are distributed in Qinghai, Gansu, Sichuan, Yunnan and other provinces. "Tibetan area" refers to the area where Tibetans live in Tibet, Yunnan Province, Sichuan Province, Qinghai Province, Gansu Province and other places, that is, "one district and four provinces". "One District" refers to the Tibet Autonomous Region, and "Four Provinces" refers to Yunnan Province, Sichuan Province, Qinghai Province and Gansu Province. The Tibetan areas of the other four provinces are mainly distributed as follows: Gannan Tibetan Autonomous Prefecture in Yunnan, Aba Tibetan and Qiang Autonomous Prefecture in Sichuan, Ganzi Tibetan Autonomous Prefecture, Yushu Tibetan Autonomous Prefecture in Qinghai, Huangnan Tibetan Autonomous Prefecture, Guoluo Tibetan Autonomous Prefecture, Hainan Tibetan Autonomous Prefecture, Hai Tibetan Autonomous Prefecture Mongolian Autonomous Prefecture, Haibei Tibetan Autonomous Prefecture, Gannan Tibetan Autonomous Prefecture in Gansu. Although Tibetan people live scattered, horse racing is their favorite activity in their bones. Horse racing is also the longest and most common mass activity of the Tibetan people in history.

From ancient times to the present, the Tibetan people have lived a nomadic life. Horses are an important tool for Tibetans in communication, production, and war. Their life and environment require them to be proficient in horseback riding. They must be trained from an early age, and horse racing was born. Horse racing is called "Dajiu" in Tibetan. This is the most popular and widely spread sport among Tibetans. Tibetan riding has a long history. According to the "Tang Shu T Tubo Biography", there was a kind of communication cavalry in Tubo, called "posters". They often carried seven-inch golden arrows to and fro between the post stations to convey signaling. According to "Yin Quotations", this kind of postman "travels hundreds of miles a day, the messenger gets on the horse like flying, and the name is the horse messenger". This shows that the riding skills of the "poster" at that time were quite superb.

Tibetan sports have a long history. As early as fourteen or five hundred years ago, the "Wangguo Festival" in the Yalong area had entertainment activities such as wrestling, sword 
fighting, and shuttlecock play. Later, horse racing, archery, and Tibetan opera were added. Beginning in 1409, at the closing ceremony of the "Morang" conference (summoned by the temple) organized by Gesha every January, three days of sports competitions were organized. Including horse racing, running, wrestling, rocking, equestrianism, archery, etc., which have been passed down to this day. For the people on the plateau, horses, like yaks and sheep, have been integrated into their lives. And the horse is also closely linked with the material needs and spiritual desires of the Tibetan people in the passage of time. For the Tibetan people, the horse has also evolved into a deep emotion that cannot be parted from, and has been integrated into the blood of every Tibetan people.

On the plateau, Tibetan ancestors have started to domesticate horses and hunted for a long time, and they have mastered riding skills during hunting. Horse is the most intimate partner of Tibetan people in daily life. It has penetrated into all aspects of Tibetan people's lives, such as grazing, traveling, and marriage. Tibetans often have horse races throughout the year, offering sacrifices to horses, praying horses, and praising horses. These have become indispensable rituals in Tibetan life. And every festival, horse racing will become an important event for Tibetans to celebrate the festival.

In Tibet, China, there are different types of horse racing. In terms of distance, it usually ranges from 10 to tens of miles, and there are also mid-range races under 10 miles or short-range races of one or two miles. For horses, there are horse races, foal races, and mares races. For riders, there are adult races, kids races, and girl races. There are also horse races without riders. The winner is the one who reaches the end first. Sometimes it also judges the horse's frame and movement. In some competitions, horse racing and riding on the clothing. There are also some horse sports that show superb riding skills and skills, such as picking up hada immediately, offering highland barley wine immediately, chopping or pulling flagpoles immediately, and performing physical performances, shooting immediately, and archery. Unlike the current standard horse racing form, the Tibetan horse racing is closer to life and better reflects the life feelings of the Tibetan people. In Tibetan areas, people not only entertain their bodies and minds through horse racing, but more importantly, build strong emotions with horses. Therefore, the horse racing culture of the Tibetans appears to have unique national characteristics. The participating horses were no longer used for farming or animal husbandry a few months before the start of the race, but instead devoted themselves to training.

It is the nature of the Tibetan people to love horses. In their eyes, "Although horses have the fur of beasts, they have the spirit and emotion of God". Horse racing is the main content of Tibetan compatriots' life and entertainment. There are countless horse races, and horse races are held in all major festivals. This is also an important manifestation of Tibetan folk customs and customs.

The horse must be well dressed up when racing. In addition to the exquisite saddle sheath and bridle on the horse's back, colored flowers are placed on the forehead, colored silk on the neck, and the tail is tied into a braid. Then tie colorful ribbons, these decorations will make the horse run into a rainbow. Secondly, the main parts of the horse should be worn. Horse equipment is 
commonly known as "six-piece horse set", including bells, horse cushions, saddles, cages, riding whips and stirrups. Wearing these horse ornaments must be very meticulous, and every rope buckle must be meticulous, because any negligence in any link may bring life to the rider. In some places, bareback horses are used to compete, increasing the difficulty of the competition. With gorgeous mounts, the participating riders must also be well dressed. Stepping on lightweight Tibetan boots, wearing gorgeous colorful clothes or tights, and then wearing a red tasseled hat, big head hat or golden flower hat, carrying a fork gun on his back, he looks extraordinarily handsome. The ancestors of the Tibetan people have attached great importance to horses for generations. Regarding the various decorations of horses, whether it is worn on the head or on the tail, the Tibetans will choose the best one. The annual jockey meeting is very important to Tibetans. Start preparing early every time. Tibetans will bring tents, wear gorgeous national costumes, and wear all kinds of exquisite accessories, from far and near to the jockey club. Although the Tibetan people live scattered everywhere, they have the same heart for horse racing. The Tibetan compatriots use the same method-holding a horse racing festival to express their love for horse racing.

There are many Tibetan horse racing festivals. Such as Northern Tibet Horse Racing Festival, Gyangze Dama Festival, Kangding Horse Racing Festival, Panpo Horse Racing Festival, Tianzhu Horse Racing Festival, Dangxiong Horse Racing Festival, Tingri Horse Racing Festival and so on. But in different regions, Tibetan horse racing festivals are also different. In Tibet, among the many horse racing festivals, Nagqu Horse Racing Festival, called "Daqiong" in Tibetan, is a grand traditional festival in northern Tibet. It is held on August 1st of the Gregorian calendar every year and lasts from 5 to 15 days. The length of the races varies, mostly about 10 kilometers. According to the age of the players, there are children and adults. According to the content of the competition, it is divided into archery, target shooting, competition, short-track sprint, Hada immediately, and barley wine offering. Sometimes it also includes a horse race similar to a dressage and there are many names. Innovative and interesting horse racing activities will often make the audience forget.

Maqu County is located in the southwest of Gannan Tibetan Autonomous Prefecture in Gansu Province. It has always had a tradition of holding mass horse races. It is also the center producing area of the Chinese famous horse Hequ horse, and is known as the three famous horses in China together with the Inner Mongolia Sanhe Horse and Xinjiang Yili Horse. As one of the producing areas of famous horses in China, Maqu has a tradition of holding horse races since ancient times. In 2012, it was named the "Hometown of Horse Racing in China" by the Chinese government and the Chinese Equestrian Association. The local jockey clubs generally have 5 events and 19 awards including speed horse racing and endurance horse racing from 1,000 meters to 10,000 meters. The competition is in line with international and domestic competitions, using a circular field, and the entire competition period is 5 days. It is usually held in mid-August, and hundreds of players from dozens of teams from 25 counties and cities in Gansu, Qinghai, Sichuan and other surrounding areas are invited to participate. In recent years, the scale and influence of Gesar Horse 
Racing Festival have been expanding, and it has become a sports event and a well-known tourist and cultural brand in ethnic minority areas in western China.

Yushu Jockey Club is the largest Tibetan event in Qinghai. Whether the people of Yushu worship the mountains and worship the gods, greet guests and send off guests, or manage marriages, they cannot do without horse racing. At that time, Tibetans dressed in bright national costumes will tie their tents scattered on the Jiegu grassland. Participate in horse racing, yak racing, Tibetan wrestling, equestrianism, archery, shooting, folk song and dance, Tibetan costume display, etc. A series of activities with extremely national characteristics will be held.

That the simple and unrestrained Tibetan people, as creators on the plateau, use their sincere and love for horse racing to show the society many Tibetan horse racing festivals with unique Tibetan cultural characteristics. It can also be said that the Tibetan people created the most important part of Tibetan secular culture-horse racing culture.

2.4 The Analysis on the Value and Predicaments of the Integrated Development of Tibetan Horse Racing Festival and Tourism

\section{1) The value of deep integration of Tibetan horse racing festival and tourism}

First, promote new economic growth points in Tibetan areas and promote coordinated and rapid regional economic development. In recent years, with the continuous improvement of residents' consumption levels and the renewal of consumption concepts, the development of tourism in Tibetan areas has ushered in unprecedented opportunities, and tourism has become an important growth point and support for its economic growth [35-36]. The deep integration of Tibetan horse racing and tourism can promote a new growth point of tourism economy in Tibetan areas. The Tibetan Horse Racing Festival has the potential for tourism development, coupled with the tourism industry's own advantages. There are basic models for tourism development, which makes it easier to develop. Not only can it increase jobs in Tibetan areas, but it can also increase the economic income of Tibetan residents in scenic areas. This will help Tibetan areas to transform their growth patterns, promote the development of Tibetan farming and pastoral areas and economically backward areas, and promote economic growth in Tibetan areas.

Second, to promote the optimization and upgrading of the industrial structure in Tibetan areas, and to shape tourism brands with local characteristics. As the horse racing festival is a folk cultural festival that Tibetan people are more familiar with, it is closely related to people's lives. It is a labor-intensive industry that requires a large amount of employment. Therefore, the employment threshold is not high, and everyone at different levels can find their own professional positioning in the horse racing festival tourism industry, which has the effect of promoting employment and reducing the unemployment rate. Tourism, as a comprehensive industry, serves a variety of tourists. It needs to provide tourists from many aspects such as tourists, travel methods, food supply, accommodation facilities, and entertainment facilities. Its services also need to change over time [37-38]. Therefore, the Tibetan Horse Racing Festival as a tourism resource can promote the development of many related industries, and its own development is relevant, extensible and inclusive. In addition, the Tibetan area itself has not yet formed a complete 
industrial system. The exploitation of Tibetan horse racing festival folk cultural tourism resources is a kind of utilization of its traditional resources, which can promote the optimization and upgrading of industrial structure, provide a solid material foundation for its industrial development, and further to improve the tourism industry system.

Third, promoting the process of urbanization in Tibetan areas is conducive to the revitalization of rural economy and culture. Firstly the horse racing festival has huge economic and social benefits. Regarding the Tibetan Horse Racing Festival as a tourism resource, the rapid development can promote the urbanization of surrounding areas. Promoting the development of tourism in Tibetan areas can well promote the development of the local economy, and promote the promotion of local soft and hard power at the same time [39-40]. Secondly, the development of the tourism industry can become a pillar industry for local economic development, promote employment growth in Tibetan areas, absorb local employment, improve the lives of Tibetan people, improve the quality of life of Tibetan people, and promote urbanization. Thirdly, in terms of promoting population urbanization, developing tourism in Tibetan areas and tapping traditional folk cultural resources can promote the development of extensive economy in Tibetan areas to an intensive economy. More emerging industries can be developed, and housing facilities can gradually improve. Improve urbanization and promote the urbanization of people.

Fourth, to meet the spiritual needs of the Tibetan people and enhance the consciousness of ethnic cultural community. As a long-developed folk cultural heritage of the Tibetans, the horse racing festival is the best demonstration of the spiritual quality of the people in Tibetan areas with its rich cultural connotations rich in Tibetan national characteristics. At the moment, the tourism industry is the most important force in my country's development industry. As a tourism resource for Tibetans, the horse racing festival has strong plasticity and is worthy of regional attention. Nowadays, people are more willing to choose tourism projects with cultural connotations. This demand is somewhat different from the traditional "tourism" type of tourism. The development of tourism resources for the horse racing festival obviously captures the key point of the change in the reputation of tourists from all over the world. The development of horse racing festival tourism can meet the needs of tourists and meet their psychological needs of "curiosity, knowledge, novelty, and difference". As a humane tourism method, it is loved by the audience and meets their spiritual and cultural needs. Moreover, compared with other tourism methods, horse racing festivals, as a kind of folk culture, still have a certain degree of interaction. Be able to emerge from the cookie-cutter tourism style, stand out, and form tourism with local characteristics. The development of horse racing festivals has a two-way effect. In the past, there was a lack of dialogue between various ethnic groups, and modern discourse often rejected some folk, marginal, and non-mainstream cultures. Think of that the culture of some ethnic regions is backward and superstitious, which is a symbol of ignorance. Continuously excavate folk culture and develop it as a tourism resource. While promoting the economic and social development of ethnic regions and the growth of the people's economy in the region, it can also promote exchanges and interactions between the two parties. Let Tibetan areas be more comprehensively 
recognized by the outside world. Thereby dispelling the mist of misunderstanding and allowing Tibetan areas to better integrate with modern life. Better promote the development of our folk culture. Promote the integration and development of national cultures. Enhance national cohesion and self-confidence. Realize the revival of Chinese traditional national culture.

2) The predicament of the integrated development of Tibetan horse racing festival and tourism Compared with developed tourism areas, tourism development in Tibetan areas started late. Both in terms of scale and experience, there are objectively many shortcomings and shortcomings, such as imperfect facilities, poor service quality, single product structure, aging form, and content. Outdated, lack of innovation, and difficulties in developing and promoting international sports tourism. The Tibetan horse racing festival also has similar problems. In-depth integration with tourism needs to resolve its dilemma.

First, the product structure is single and the facilities are not perfect. Tibetan areas have a special geographical location, mostly located in plateau areas, with long cold winters, high altitudes, long transportation lines, fragile ecological environment, weak transportation and other infrastructures, many natural disasters, and environmental constraints on tourism development. Moreover, most Tibetan areas are relatively poor. The level of cultural education is relatively low, the population is scattered, the population size is small, centralized management is inconvenient, and population mobility is low. The industry is dominated by traditional industries, the scale of the cultural industry is small, the structure of tourism products is single, and the development is intensive. Therefore, in order to develop the tourism culture of the horse racing festival, it is also necessary to overcome the inevitable poor infrastructure in Tibetan areas. Especially in the more remote farming and pastoral areas, due to factors such as the terrain and environment, there is a lack of cultural atmosphere and atmosphere. To make local villagers aware of the cultural value of the horse racing festival and recognize its value as a tourism resource, it is also necessary to actively carry out cultural activities education and training and improve the infrastructure of cultural activities.

Second, the product form is aging and the service quality is poor. Tibetan areas are the key poverty alleviation areas of the country, with low population education, a large proportion of the rural poor, and a low overall economic level. Therefore, raising the income level of the poor in Tibetan areas and improving their living conditions will be the focus of the country's fight against poverty. The overall economic level of Tibetan areas is low, and accordingly, there is an imbalance in capital investment in various fields such as culture, economy, and politics. There is no reasonable allocation of resources, especially cultural resources have not been effectively and rationally used, and the level of development of cultural undertakings is low. In Tibetan areas, due to objective conditions, the government has invested more experience in economic development. Insufficient investment in cultural undertakings, some villages cannot even find an open space for local villagers to use as infrastructure for cultural activities. On this basis, relevant cultural management personnel also lack relevant cultural knowledge training and cultural service capabilities are low. 
Third, the product content is outdated and lacks innovation. Not only is there a shortage of tourism resources in Tibetan areas, but the ideology of managers is also relatively conservative and lacks a certain sense of innovation. As a result, the content of regional tourism products is relatively obsolete and lacks innovation. As far as the regular development of horse racing festivals is concerned, the content of the annual competitions held in each region is similar, with insufficient features and insufficient modern elements. Secondly, the cultural industry management system is not sound, lacking standardized guidance and supervision mechanisms and incentive policies. Local government departments rarely dig out the significance and value of the folk culture of horse racing festivals as tourism cultural resources. Some relevant preferential incentive policies have not been implemented, resulting in difficulties for local cultural industries to develop outwards and difficulties for foreign cultural industries to import inwards.

2.5 A Case Study of the Practice of Integrated Development of Tibetan Horse Racing Festival and Tourism

1) The practice of integrated development of tourism and horse racing festival in Chaqing, Nagqu Qiangtang, Tibet autonomous region

Located between Tanggula and Nyainqentanglha, Nagqu in Tibet is an important town in northern Tibet, with an average elevation of about 4500 meters. The Nagqu Qiangtang grassland is an important animal husbandry area in the Tibet Autonomous Region. The Tibetan people who have lived here since ancient times are known for raising horses, training horses, riding and shooting. It has a unique folk customs of horse racing that is rich in grassland nomadic culture. The horse racing on the Tibetan Plateau is the most famous of the Nagqu Qiangtang Chaqing Horse Racing Festival, which is one of the grand festivals for herdsmen on the Qiangtang grassland. The Nagqu Qiangtang Chaqing Horse Racing Festival has played an active role in spreading Tibetan culture, promoting the economic development of Nagqu, and establishing the tourist image of Nagqu. It constitutes the cultural motivation of traditional national sports tourism activities with horse racing as the main content.

First, enhance the influence of Nagqu Qiangtang Chaqing horse racing brand festival activities.

The Nagqu Qiangtang Chaqing Horse Racing is a product of pastoral animal husbandry economic and cultural type. When the way of livelihood changes, especially with the implementation of national poverty alleviation. In order to solve the problem that water and soil cannot feed people, the nomads who live by water and grass were removed from the unsuitable environment, settled and led an urbanized life. Horses are no longer the only nomadic tool, and grazing travel is gradually replaced by motorcycles. With modern civilization infiltrating the Qiangtang grassland, the living environment has changed. Especially when young herders entered the city to work, their ideology changed to a certain extent after being exposed to other cultures and modern lifestyles. The pursuit of modern life has become a fashion, gradually diminishing horse breeding and training, and adversely affecting the inheritance and development of horse 
racing. In this regard, in order to enhance the influence of Nagqu Qiangtang Chaqing horse racing brand festival activities. First of all, it must be guided by the "Thirteenth Five-Year Plan" of the Tibetan government. "It is necessary to accelerate the development of cultural undertakings in Tibet, build an important cultural protection area with Chinese national characteristics, promote the innovative development of excellent traditional culture, and extensively carry out various mass cultural activities". From the height of cultural self-confidence, integrate into the cultural construction and tourism development of Nagqu. Innovate the content and methods of the horse racing festival and expand the development space of the horse racing festival. Second, we must increase institutional innovation and capital investment. Provide economic support for the horse racing festival, build a good horse racing cultural exchange and investment promotion platform. Third, it is necessary to fully tap the cultural resources of horse racing and cultivate the living soil of horse racing. Maintaining the characteristics of horse racing culture, make the Nagqu Qiangtang Chaqing Horse Racing Festival a cohesive force and driving force leading the progress of social civilization. Promote the inheritance and development of the Nagqu Qiangtang Chaqing Horse Racing Festival and promote national culture.

Second, to make the Qiangtang Chaqing Horse Racing Festival a Nagqu tourism brand.

First of all , take the Tibetan government's proposal to "build an important world tourism destination, promote the deep integration of excellent folk culture and tourism industry, promote the development of tourism and culture integration, and shape tourism brands" as the starting point. Use the models of "culture + ", "tourism + " and "Internet + " to realize the innovative integration of tourism brand development methods for horse racing festivals. Grasp the development and growth of market entities of "horse racing + cultural tourism" and stimulate the vitality of the integration of "horse racing + cultural tourism". Do a good job in the development of the "horse racing + cultural tourism" industry, improve industrial efficiency and added value, and innovate the development of the "horse racing + cultural tourism" business format. Then, it is necessary to vigorously make use of Nagqu's unique advantages in tourism resources. Make the Qiangtang Chaqing Horse Racing Festival a grassland ecological sports tourism brand with characteristics of Nagqu region. Next, it is necessary to guide farmers and herdsmen to participate widely in the "horse racing, setting up stage, economic and trade singing" advocated by the government. Provide them with appropriate venues and stalls to promote self-produced livestock products and become a channel for herdsmen to get rich, help alleviate poverty, and open up a new way to promote local economic development. Last, to make the Qiangtang Chaqing Horse Racing Festival a Nagqu tourism brand. It is recommended to establish a horse racing festival dedicated organization and a professional horse breeding and training base. Develop less dangerous horse racing events that tourists can participate in. Let visitors experience the cultural connotation of horse racing while participating.

Third, strengthen the research on the culture of Nagqu Qiangtang Chaqing Horse Racing Festival.

At the opening ceremony of the Asian Civilization Dialogue Conference, the leaders pointed 
out: "The sustainable development of civilization requires not only the passing on of the fire and the protection of generations, but also the need to adapt to the times and bring forth the new". This important argument of the leader is important to the promotion of Nagqu Qiangtangcha. The inheritance and development of the Youth Horse Racing Festival in the new era is of great significance. Local cultural and tourism departments should take the core socialist values as the guide and draw nourishment from the national culture. Make full use of the national intangible cultural heritage protection policy, organize experts and scholars to explore the cultural connotation of the Nagqu Qiangtang Chaqing Horse Racing Festival. Provide theoretical support for the development of horse racing festivals and a series of cultural activities. It fully demonstrates the unique national cultural charm of Nagqu and constitutes people's unique and beautiful memory of the national culture of the horse racing festival. Promote the coordinated development of horse racing culture and Nagqu tourism industry, and create a national cultural brand with characteristics of the Qiangtang grassland. In the excavation and research, it is necessary to innovate the content and form of the Nagqu Qiangtang Chaqing Horse Racing Festival, to understand the pulse of the times, to understand social changes, and to innovate expressions, so that the horse racing festival as an excellent traditional culture embraces modern life. Only creative transformation and innovative development can activate the "spring water" of the horse racing festival culture and radiate new vitality. It not only promotes the integration of Nagqu horse racing culture and tourism, but also becomes the main front for spreading spiritual civilization. Reflect the characteristics of the times and enhance attractiveness, charisma and cohesion. Build a spiritual home for all ethnic groups, and spread a positive and healthy life concept for the masses of herdsmen.

To sum up, the Nagqu Qiangtang Chaqing Horse Racing Festival is a grand folk festival for herdsmen on the grasslands of northern Tibet. It has a unique folk culture with characteristics of grassland nomads. It has played an important role in spreading Tibetan culture, promoting Nagqu's economic development, and establishing Nagqu's tourism image and brand. In order to better promote the integration of Nagqu horse racing and tourism, government departments must strengthen planning guidance, increase capital investment, provide preferential policies, and pay attention to inheritance and protection. And closely integrated with the times, inject new elements into Nagqu's tourism development. Make the Nagqu Qiangtang Chaqing Horse Racing Festival a special business card of Nagqu folklore tourism. Let tourists feel the charm of horse racing culture and become a new highlight of Nagqu's tourism development.

2) The practice of integrated development of Shangri-La Horse racing festival and tourism in Yunnan Province

In recent years, various major festivals and events held by Shangri-La, as important content of tourism nodes, have played a vital role in further exploring the tourism cultural market and promoting the inheritance and dissemination of national traditional culture. The Dragon Boat Festival is one of the major annual traditional festivals in Shangri-La. As the oldest national traditional race in Shangri-La and the most popular Dragon Boat Festival project, it not only 
further promotes and inherits the long-standing ethnic culture of Shangri-La, and fully demonstrates its unique folk customs. The propaganda platform for amorous feelings and beautiful natural scenery is also an important bridge for Shangri-La City to strengthen foreign exchanges, enhance friendship, enrich Shangri-La's cultural connotation, and promote and protect the Shangri-La brand. Its predecessor was the "May Jockey Club" organized by the people spontaneously during the Ming and Qing Dynasties. In 1997, it was officially renamed "ShangriLa Dragon Boat Race Festival” and became a legal holiday in Shangri-La.

The competitions and performances of the 2018 Diqing Shangri-La Dragon Boat Festival Horse Racing Festival mainly include equestrian competitions (speed, horsemanship, horse riding), national and folk traditional sports individual events (archery, crossbow shooting), and intangible cultural heritage works (horse supplies) exhibition reviews and other content. Activities and events cover a wide range and rich content. The excellent traditional culture of the horse racing festival is concentratedly displayed. During the horse racing festival, Shangri-La City also held a series of activities such as equestrian performances, the second Balagezong Music Festival, and the "Balaguezong Cup" International Motocross Grand Prix. The 2018 Shangri-La Horse Racing Festival attracted 230,000 tourists from all over the country, far exceeding 110,000 in 2017. The Horse Racing Festival effectively boosted Shangri-La's tourism growth.

Since being discovered by people, Shangri-La in Yunnan has won a good reputation in the tourism industry for its unique natural resources. However, with the changes in people's tourism demand in recent years, tourism projects characterized by highlighting ethnic cultural resources. It has become an important part of Shangri-La tourism. For example, in order to dig deep into national cultural tourism resources. Let tourists have a better understanding and feelings about their own nation. The Shangri-La government deliberately designed its original horse racing event. Only centering on the theme of traditional horse racing, there have been developed horse speed races including men's 1,000, 3,000, and 5,000 meters, and women's 1,000, 2,000, and 3,000 meters. Men's 1600-meter horse racing, horse racing to pick up hada, horse racing shooting and other men's horsemanship competitions. 800-meter yak race. Mountaineering, archery, crossbow shooting, bull pull bars and other unique sports competitions. Nowadays, in order to enrich the tourist experience, exhibition games have been added between horse racing events. Such as Diao Guo Zhuang, Diao Xian Zi, Reba dance and so on. In order to strengthen the attractiveness of the overall activities and expand the overall benefits of traditional sports festivals. From the perspective of tourism during the Shangri-La Horse Festival, how to use traditional sports and cultural resources to integrate tourism. Creating characteristic tourism products that can attract people to participate is a top priority. And these two seemingly unrelated industries. The ability to achieve a good coordinated development of the industry shows that sports and tourism have the characteristics of being connected in connotation. The main reason is that nature and characteristics are similar. For example, they are all social activities that people participate in to meet their spiritual and cultural needs. Both have similar characteristics such as nontransferability, non-materiality, and the simultaneity of product production and consumption. In 
addition, the distinctive themes of traditional sports festivals can be transformed into easily recognizable tourism logos. The high-level tourism service quality can provide support for the event. This shows that the integration of the two will produce great comprehensive benefits.

As the scale of Shangri-La sports events continues to expand, the number of people who come to travel and watch the games has increased year by year. Since the development of festival tourism at the Horse Racing Festival, the number of tourists during this period has doubled every year. In the year when the event was held alone, 100,000 people participated. During this period, the income from the tertiary industry hotel service industry was very considerable. With the increasing promotion of the Shangri-La horse racing brand, the work of attracting investment is very gratifying. For example, during the 2012 horse racing festival, the investment attraction was 460 million yuan, and the annual tourism output value reached 5.812 billion yuan, 31 times that of 10 years ago. Now there are more and more foreign merchants who come to Shangri-La to build new hotels and restaurants. In the first half of 2013 alone, there were 9 new hotels and a capital investment of 306 million. This has made a big contribution to the development of Shangri-La's tertiary industry. It is not difficult to see that the horse racing festival has been successfully held in recent years, and the horse racing festival has become an important brand of Shangri-La tourism. And to stimulate local economic growth through unique charm. For this reason, the horse race has been extended from the original one day to three days. Women's competitions have been added in the past two years. The economic benefits brought by event tourism are more prominent. For example, during the 2014 Shangri-La Horse Racing Festival alone, the prefecture received 130,250 tourists from home and abroad, and realized tourism income of RMB 511.0516 million. Therefore, the development of sports events, especially those with distinctive features and strong viewing capabilities, will have a great comprehensive tourism effect. The horse racing festival has become a business card to promote the new tourist attractions of Shangri-La.

The holding of the horse racing festival is inextricably linked with Shangri-La's tourism industry, which determines that there must be an intricate interactive relationship between the two. Analysis of the composition of the two is nothing more than three factors: First, the participants and tourists are the main body of the competition and tourism activities. The second is events, tourism resources, the objects of events and tourism activities. The third is the mediator of sports tourism and event tourism activities. Therefore, the two are destined to achieve mutual benefits only when they integrate and develop. First of all, the funding preparation and development of traditional sports festivals should be incorporated into the overall planning of local tourism. The municipal government should regard the annual sports festivals as an important work indicator. Actively use the conditions of the municipal government to absorb social funds as much as possible to prepare various funds and infrastructure construction for the event. For any sporting event, whether traditional or modern, if it only relies on government funding, one is that the government invests too much, and the other is that it cannot mobilize and give play to the enthusiasm of the society to participate in it. Therefore, sports festivals must be developed in 
collaboration with tourism to make full use of social resources to improve the conditions of the event. Secondly, the development of tourism at any festival must not lack marketing activities. The difficulty of traditional sports festival tourism development and marketing lies in the fact that the marketing team must have a marketing background in the tourism industry and be good at digging out the marketing points of traditional sports festival activities. That is, compound talents who understand sports industry and tourism industry management. Therefore, the establishment of a traditional sports festival tourism development model requires internal training of professional talents. Or hire a professional marketing company to plan through outsourcing, to achieve active marketing to the target source market, and to provide good information supporting services for participants and spectators. Finally, the coordinated development model of traditional sports festivals and tourism should fully explore tourism products and derivative products related to traditional sports, including souvenirs and mascots. Through the development of additional products, tourism enterprises can also obtain considerable income and a relatively stable source of tourists. A win-win situation of interactive development between festivals and tourism is truly realized.

3) The practice of integrated development of Maqu "Gesar" horse racing festival and tourism in Gansu province

The Chinese Maqu "Gesar" Horse Race is a traditional horse racing event held to commemorate the thousandth anniversary of King Gesar. Twelve sessions have been successfully held today. So far, the Chinese Maqu "Gesar" horse race has become the largest horse race in western China. Not only has it promoted the development of the horse racing industry, it has also become a catalyst for Maqu to build its reputation as the "Hometown of Horse Racing in China". The Maqu Horse Racing Conference is a traditional sports event integrating competition, viewing and entertainment. The Horse Racing Conference adheres to the spirit of "inheritance, promotion, development, and innovation", with the theme of "primity, thrift, and harmony". Take the "government guidance, association sponsorship" approach. The scope of the competition involved five provinces including Gansu, Qinghai, Sichuan, Xinjiang and Zhejiang, with more than 500 horses participating. At the same time, yak, Tibetan sheep and Tibetan mastiff appraisal and exhibition activities will be held. It shows the vigorous spirit of the children of all ethnic groups in Maqu and the brave and heroic posture of horse racing athletes. Enhance the popularity and reputation of Maqu in the province and even the whole country. Promote Maqu to a new level in inheriting culture, publicizing its characteristics, developing tourism, cultivating industries, invigorating commerce, and accelerating development. The industry chain derived from the horse racing conference is relatively long, including the horse racing industry such as the construction of horse racing venues, horse training, harness processing, feed processing, and "horse fan" training. It also has a greater role in promoting the market development of extended industries such as urban tourism, leisure and entertainment, transportation, transportation, hotels, restaurants, and advertising media.

First, the development of Gannan Tibetan horse racing industry. 
The accelerated development of the Chinese Maqu "Gesar" Jockey Club and the country's active support for equestrian sports will greatly promote the rapid development of Gannan Tibetan horse racing industry. In recent years, Maqu "Gesar" horse racing has developed rapidly and accumulated rich experience. It has made great progress in the hardware environment of the competition and the level of competition organization. The development of the horse racing market has achieved positive results, and the competition is gradually becoming industrialized and branding. One is to speed up the construction of hardware facilities such as venues and equipment. The primitive and vast grasslands and the inheritance of horseback ethnic groups are the basic conditions for Maqu to hold large-scale horse races. As of November 15, 2020, Maqu has successfully held the 12th China Maqu "Gesar" Horse Racing Conference. The racecourse is a training base for equestrian and speed horse racing in Western China, and the equipment and facilities are gradually being completed. The second is to drive market demand in the production of horse gear and horse decorations, horse breeding and training, and horse material processing, as the scale and influence of the China Maqu "Gesar" horse racing conference continue to expand. The market demand for the production of harness and horse decorations, horse training, and horse material processing will continue to increase. It can not only promote the employment of local herdsmen, but also stimulate the development of the regional economy. It can also provide a variety of jobs with the theme of "horse". For example: Feed processing, nursing, training, horse training, harness production, facility management, ancillary services, veterinarians, horse club management, security and other related industries will require a lot of human resources. The third is to cultivate the "horse" profession and the emergence of "horse fans", making the horse racing market take shape. With the gradual commercialization of horse racing, starting from 2004, it will be held in Maqu County, Gannan Prefecture from August 13th to 17th every year. The conference attracted hundreds of horse racers from five provinces including Gansu, Qinghai, Sichuan, Tibet, and Inner Mongolia to gather in the Maqu Tashitan grassland. They competed against each other and showed their abilities. The participating teams have gradually grown from the first 20 teams to the current 32 teams. At the same time, the number of tourists and people has increased from more than 40,000 to more than 100,000. At present, the 12th Gesar Horse Racing Conference has been successfully held. The prize money for the 10,000-meter endurance horse racing championship has been increased from 50,000 yuan in the first to 200,000 yuan in the seventh. The total prize money is as high as one million yuan. The national traditional sports event with the largest scale, the largest number of participating teams, the highest prize money, and the most influential in the western region also played a unique role in promoting economic and trade circulation and friendly exchanges in the surrounding areas.

Second, the development of the extension industry of the Maqu Gesar Horse Race in China.

The Gesar Horse Race has attracted participation and attention from all walks of life at home and abroad. High-level horse racing events will surely promote the development of related industries around the theme of "horse". The horse racing market has huge potential and a long industry chain. The cohesion and influence of the horse racing industry will surely drive the 
development of urban tourism, culture and entertainment, transportation, transportation, hotels, restaurants, advertising and media and other extended industries. One is to become a powerful guarantee for promoting the development of tourism, culture, and entertainment markets. The rise of the horse race meeting in Maqu will become the carrier for the development of tourism, culture and entertainment in Gannan. At the same time, it is necessary to use the tourism art festival as the carrier to actively build the Nine-Color Gannan Shambhala brand, promote the development and prosperity of the cultural industry, and force the flourishing development of the tourism cultural industry. The Maqu Gesar Horse Racing Tournament has been well-known at home and abroad as a wonderful work of the Nine-Color Gannan Shambhala Tourism Art Festival. The five major tourism brands: "First Bend of the Yellow River in the World", "Birthplace of Gesar", "The World's Largest and Most Beautiful Wetland Grassland", "Hometown of Horse Racing in China" and "Hometown of Tibetan Folk Songs" have moved out of Gansu and into the world. The second is to promote the integrated construction and development of restaurants, hotels, transportation, and transportation. With the rapid development of Gesar horse racing and the improvement of people's consumption level. At that time, a large number of tourists from home and abroad will be attracted to Maqu to watch competitions and sightseeing tours. The market demand in catering, accommodation, transportation, transportation and other fields will increase. These conditions are not only necessary to ensure the success of the event. It is also a strong guarantee for a large number of "horse fans" and tourists who "eat roasted whole lamb, drink butter tea, sleep in tents, convenient rides, and smooth transportation". Therefore, the development of Gesar Horse Racing will surely promote the integrated construction and development of catering, hotels, transportation and transportation in Maqu city. The third is the theme of horses, guided by the government, sponsored by the association, and national economic and cultural singing. The first song is green, Gesang is striving for beauty, eagles flying and cranes dancing, antelopes running and deer singing, the scenery is picturesque. Every year on August 13th, the China Nine-Color Gannan Shambhala Tourism Art Festival and Maqu Gesar Horse Race will enjoy "the first bend of the Yellow River in the world", "the birthplace of Gesar", and "the world's largest and most beautiful wetland grassland", "The Hometown of Horse Racing in China" and "Hometown of Tibetan Songs" kicked off on time.

4) The practice of integrated development of Litang horse racing festival and tourism in Sichuan Province

Horse racing has a long history and various forms. The Litang Jockey Club originated from the Litang folk traditional festival "June Zhuanshan Meeting". In history, in June every year in the Tibetan calendar, when the entire grassland is green and the flowers are in full bloom, people will hold a grand jockey meeting to worship the sacred mountain in accordance with the custom. So far it has become a unique ethnic folk cultural and sports activity in Litang. Litang horse racing culture is a life culture rooted in the Maoya prairie. It is a large-scale cultural complex integrating folk entertainment, folk songs and dances, local operas, traditional crafts, and material exchanges. It is the most beautiful cultural business card showing the ethnic folk culture of the Kham-Tibet 


\section{Design Engineering}

area. Under the leadership of the horse racing festival, it is organized in multiple festivals to vigorously promote excellent ethnic folk culture, promote the integrated development of the cultural and tourism industry, and spare no effort to maintain the stability and unity of ethnic regions. In 2008, Litang Jockey Club was included in the Sichuan Provincial Intangible Cultural Heritage List. In August 2019, Litang County was awarded the "Hometown of Horse Racing Culture in Sichuan" and "Hometown of Ethnic Equestrianism in Sichuan Province" by Sichuan Province. On August 15, it was named the "Hometown of Horse Racing Culture in China" by the Chinese Folk Artists Association.

In recent years, with the vigorous development of outdoor sports, in order to further deepen the "sports + tourism" development strategy, promote the popularization and development of equestrian sports, and promote the development of the cultural tourism industry in Litang County. Take "Litang Horse Racing" as the goal of creating a classic folk tourism brand in Litang. The local horse racing competition "Litang, the hometown of horse racing culture" was held, the horse racing association was established, and the standard racecourse was built. Horse racing events are held every month from May to October. The finals will be held in August, and through vigorously carrying out "equestrian competitions", we will strive to make Litang horse racing a normal and high-level event. Litang, which has a rich history of horse racing, displays horse racing culture accumulated over hundreds of years in every area of the "Sky City" through regular horse racing events held every year. Open up a broad world of tourism in the whole region by means of "folk sports + tourism". While promoting the popularization and development of equestrian sports in Litang County, it further enhances Litang's tourism reputation, and enhances its influence and attractiveness. Let friends from other places know more about Litang and fall in love with Litang through horse racing, and promote the development of Litang tourism industry better and faster.

Litang County organically integrates horse racing and commerce, and builds many sections integrating wholesale and retail agricultural special product promotion, e-commerce, and tourism. It is a business platform integrating exhibitions and sales, singing and dancing performances, horse racing activities, food festivals and many other sectors. In this way, we can tap the potential of consumption, promote consumption and poverty alleviation, and help alleviate poverty. The reputation of "Equestrian Hometown, Prairie Pearl" is well-known everywhere. The successful experience of the Litang Horse Racing Festival and the integrated development practice of tourism in Sichuan Province is as follows: First, Litang insists on using cultural people to stimulate strong endogenous motivation. The second is to insist on establishing a business based on culture and leading the development of tourism in the whole region. The third is to insist on strengthening the county with Wen to build a city of plateau poetry. Litang horse racing culture has been passed down for a long time. Since May 2019, besides horse racing as the theme, horse racing activities have also covered sports events and ethnic art. The purpose is to hold a comprehensive event that integrates traditional sports competitions, national traditional cultural displays, and leisure travel. Holding annual horse racing events is an important measure for the county to deepen its "sports + tourism" development strategy. At present, Bayi Racecourse is the 
most standard and well-equipped horse racing venue in Ganzi Prefecture, and strive to build the "Litang Horse Racing Event" into a well-known classic folk tourism brand in the country.

5) The practice of integrated development of tourism and Yushu Horse racing festival in Qinghai Province

Qinghai Yushu Horse Racing Festival is the largest Tibetan event in Qinghai. Whether the people of Yushu worship the mountains and worship the gods, greet guests or send off guests, or manage marriages, they cannot do without horse racing. At that time, Tibetans dressed in bright national costumes will tie their tents scattered on the Jiegu grassland. Participate in activities with ethnic characteristics such as horse racing, yak racing, Tibetan wrestling, equestrianism, archery, shooting, folk song and dance, and Tibetan costume display. It is held on the Jiegu Grassland of Yushu Tibetan Autonomous Prefecture from July 25th to August 1st every year. Apart from visiting, tourists can also sing and dance with the Tibetan ethnic group to enjoy the grassland ethnic event.

The Yushu Horse Racing Festival is the most representative festival in Yushu Tibetan area and even Kham Tibetan area, with strong local ethnic and artistic characteristics. After years of development, evolution, and accumulation, it has not only become an organic part and epitome of Yushu Tibetan culture, reflecting the history, customs, culture, religion, and aesthetic orientation of Yushu Tibetans, but also exerting social interaction, socialization, social adjustment, social control and other functions. It affects the social psychology and behavior patterns of the Tibetan people in this area.

On July 25, 2019, the Qinghai Yushu Prefecture Traditional Horse Racing Festival kicked off on the Tashiko Grassland, opening the Kham Tibetan Happy Season. With this as a sign, Yushu ushered in this year's tourist season. Representative teams from Yushu Prefecture and the 6 counties (cities) under its jurisdiction participated in the annual opening ceremony of the horse racing festival. People sang and danced to welcome the joyous horse racing festival.

At the opening ceremony of the 2019 Yushu Traditional Horse Racing Festival, Snowy Gesar Culture and Art Festival and Sanjiangyuan Water Culture Festival. The scenes of milking cows, kneading sheepskin, kneading wool and other labor scenes are all moved into the scene of the horse racing festival. The National Unity Yi Dance and "Singing Folk Songs for the Party" won enthusiastic cheers and applause. The equestrian performance accompanied by high-spirited folk music brought the opening ceremony to a climax. This year's Yushu Horse Racing Festival lasted for 5 days. In addition to horse racing, it was supplemented by various cultural activities, attracting tourists from all over the country.

This "Three Festivals" will show the theme of Yushu "One Product" Sanjiangyuan Water Culture. "Yite" Gesar culture. "Four Wonders" horse racing culture, song and dance culture, costume culture, tent culture. Taking into account traditional equestrian performances, yak races, folk sports competitions, cultural tourism project promotion and economic and trade activities. Highlight the original cultural characteristics of Yushu, enhance the cultural highlights of the masses, and create highlights for tourist experience. Further inherit the excellent national and folk 
culture, enhance the influence of Yushu brand festival activities, and promote the coordinated and balanced development of the regional cultural tourism industry.

2.6 A Strategic Study on the Integrated Development of Tibetan Horse Racing Festival and Tourism

1) Pay attention to the preservation of the horse racing festival culture and cultivate the Tibetan horse racing festival global tourism model

Only by fully retaining the true connotation and authenticity of the horse racing festival culture can the horse racing festival be well developed and utilized as a tourism resource. The reason why history and culture can provide reference for later generations, among them, the authenticity of history is particularly important. As a traditional folk cultural festival of the Tibetan people, the horse racing festival has its unique cultural connotation, which symbolizes the bravery, sturdy, good riding, and bold national character of the Tibetan people. Only when the original is preserved, and when it is recognized by tourists from all directions as a tourism resource, can tourists truly appreciate the vitality of the Tibetan people and the courage of the Tibetan people. Therefore, to develop tourism resources for horse racing festivals, we need to focus on sustainable development. Under the premise of fully excavating its cultural value and retaining its cultural advantages, analyze and make decisions on its development direction. In addition, in the development process, we should uphold the people-oriented belief and use the horse racing festival as the carrier of Tibetan culture. As the carrier of people's lives in Tibetan areas, it improves the material conditions of local villagers and retains the cultural connotation of the horse racing festival. With the theme of promoting its core cultural values, gradually build a tourism industry for horse racing festivals. Secondly, the in-depth integration and development of Tibetan horse racing festival and tourism must take the road of global tourism model development. Through the comprehensive and systematic optimization and improvement of regional tourism resources, related industries, ecological environment, public services, institutional mechanisms, policies and regulations, and civilized quality, the organic integration of regional resources, the development of industrial integration, and social co-construction and sharing are realized. Use tourism to drive and promote coordinated economic and social development [41-42].

2) Improve various basic service facilities and create a boutique tourism route for the Tibetan horse racing festival

As Tibetan areas are affected by factors such as climate, geography, environment, and transportation, the development of tourism is relatively slow. Therefore, firstly, in order to develop the horse racing festival as a tourism resource, the government of the Tibetan region needs to invest funds to continue to analyze and study the geographical environment of the Tibetan region, and find the most suitable measures and programs for the development of tourism in the Tibetan region. Secondly, can also keep close contact with neighboring provinces and cities, and make use of all the resources available around them. Strengthen the construction of the transportation network and further promote internal and external communication. Finally, you 
can make good use of the Internet and use the Internet to create a culture of horse racing. To spread the horse racing festival culture to the outside world through the Internet, so that more potential tourists can understand the horse racing festival culture, generate tourism interest, and expand the potential market. In order to promote the integrated development of sports tourism and enrich holiday sports tourism products, the Chinese government has released 5 batches of 90 sports tourism routes for the Golden Week of the Spring Festival and the Golden Week of October. As Tibetan horse racing festivals are mostly held from July to August, they have not been selected as the recommended list of "Golden Week Sports Tourism Boutique Route". The creation of a boutique tourism route for the Tibetan horse racing festival have played a positive role in promoting the integrated development of the sports industry and the tourism industry, guiding and satisfying the people's diverse sports tourism needs during holidays, and expanding sports tourism consumption.

3) Taking advantage of the "One Belt and One Road" opportunity, launch an experiential Tibetan horse racing festival tourism project

The "One Belt and One Road" initiative is the best opportunity for China to develop its tourism industry. On the one hand, the deep integration of Tibetan horse racing festivals and tourism should take advantage of the opportunity of the "One Belt and One Road" initiative to expand the market to countries along the "One Belt and One Road" initiative. Let the culture and products of the horse racing festival go abroad and realize the "going out" of cultural undertakings and industries. On the other hand, sports and tourism-related departments should also earnestly implement the "bring-in" strategy to attract tourists from countries along the "One Belt and One Road" initiative to Tibetan areas. Let foreign tourists understand the culture of the Tibetan horse racing festival, and use the window of the horse racing festival to let foreign tourists enter the Tibetans and fall in love with the Tibetan people and culture. In order to achieve the above goals, the government needs to increase investment in horse racing festivals, increase publicity, cultivate and support horse racing festivals as a key tourism industry, and use the development of horse racing festivals to drive the development of related industries. In addition, the government needs to pay attention to the villages close to the border area. The border location is special and has excellent geographical advantages for the development of tourism. In the context of the construction of the "One Belt and One Road" South Asia corridor, the government can develop border tourism as a horse racing festival. In order to promote the integrated development of horse racing and tourism. The types of sports tourism items mainly include competition type, competition type, training type, etc. With the continuous escalation of sports consumption levels, spectator tourism can no longer meet the needs of tourists, and the demand for experiential tourism is growing rapidly, especially for high-end experiences. At present, the Tibetan horse racing festival is mainly for competition and watching, but lack of experience. Therefore, it is necessary to launch an experiential Tibetan horse racing festival tourism project. At the same time, horse racing festivals should be set up for specific time periods, such as Spring Festival, Ching Ming Festival, Dragon Boat Festival, Labor Day, Mid-Autumn Festival, National Day 
Race and other series of festivals. The integration of horse racing and tourism needs to pay more attention to people's experience, which can upgrade human's pure play behavior into a spiritual sublimation process of challenging oneself, which is in line with the development trend of consumer experience tourism [43-44].

4) Introduce tourism management talents to develop tourism resources for the Tibetan ice and snow horse racing festival

To develop the Tibetan horse racing festival as a tourism resource, it is inseparable from the support of professional tourism talents [45-46]. Therefore, sports and tourism related departments need to make full use of national policies. Introduce talents with management expertise and carry out professional training. Strengthen its training on cultural knowledge of horse racing festivals and improve its service skills. Let all staff related to the horse racing festival have professional skills and professionalism. In addition, attention should be paid to the introduction of innovative and high-quality talents. Nowadays, the country advocates green tourism and needs to make good use of national policy advantages to create an innovative cultural industry for horse racing festivals while ensuring sustainable development. The ice-snow grassland horse racing is a traditional Mongolian sports event, mainly including horse racing, horse riding, horse picking, Mongolian horse beauty pageant and many other activities with ethnic characteristics. The Swiss Ice Lake Horse Racing Festival is a top international horse racing event. It has a history of one hundred years from 1907 to the present. The competition events include flat speed horse racing, harness racing, and individual ski horse racing. At present, China's ice and snow sports have achieved unprecedented development. Taking advantage of the important opportunity of the 2022 Winter Olympics in China, taking ice and snow sports as a new breakthrough, develop the Tibetan horse racing festival ice and snow tourism resources, and promote the popularization and improvement of ice and snow horse racing. This will further enhance the attractiveness of the horse racing festival tourism itself and form a good domestic Tibetan horse racing tourism atmosphere.

\section{CONCLUSION}

Sports are enriched by tourism, and tourism is enriched by sports. As the trend of the integration of sports and tourism becomes more and more obvious, sports as a novel form of experience has become a new bright spot in the modern tourism industry, and the integration of sports and tourism is driving the formation of new trends in business development. To promote the transformation and upgrading of tourism, the key is to give full play to the quality improvement value and boosting role of sports, so that the two can reflect each other, and build a tourism development landscape that is full of vision, deep experience and integration. First, implant sports items to gather popularity and expand consumption growth points. The key to sports is to make projects, and the key to travel is to make markets. To expand tourism consumer groups, it is necessary to grasp the availability of resources, grasp the relevance of "tourism +", improve the adhesion of "+sports", and turn "tourism + sports" articles into industrial products 
and market benefit. Second, create high-quality events to gather business atmosphere and activate new industry momentum. Event activities are the highlight of sports events. They can make full use of the elements of local attractions to provide tourists with sports services throughout the entire process and time and space, derive popular sports products and meet tourists' all-round experience needs. The introduction of new sports event elements and every new combination of tourism resource elements is a new development path choice, which will activate a new industry development momentum. Third, give full play to the brand effect to gather local atmosphere and expand urban influence. One is to carefully cultivate fitness and leisure brands to release the attractiveness of tourist boutiques. The second is to design and promote leisure sports routes to break the limitations of single tourism. The third is to focus on promoting the construction of major sports projects to enhance the reputation of the tourist city.

The integrated development of traditional national sports and tourism is the result of the multilevel, multi-directional, multi-path integration and borrowing of the two major industries. Integrated development can only achieve a win-win situation in the increasingly fierce competitive environment by fully infiltrating, intersecting and complementing each other in the fields of economy, culture, and services, reducing costs, saving resources, and refining the essence. Relying on the main ideas of government-led, enterprise-assisted, and market perfection, we can clear the obstacles of integration, explore the points of integration, optimize the details of integration, fit the traditional national cultural tastes, and position the sports tourism function, thereby promoting the all-round integration of traditional national sports and tourism. National traditional sports tourism product system to enrich the construction of tourist destinations. The industrial integration and development of national traditional sports and tourism has important social, economic and ecological values. In order to meet the people's increasing demand for folk sports, tourism and leisure, the integrated development of traditional ethnic sports and tourism should receive global attention, global cooperation and global promotion. To promote the upgrading of the traditional national sports tourism industry, improve the quality of traditional national sports tourism products and services, increase the radiation scope of the education and inheritance of traditional national sports, promote the promotion of national culture and strengthen national self-confidence.

The state should issue documents related to the development of horse racing festivals to promote the deep integration of Tibetan horse racing festivals with tourism. The local government should implement the plan for the development of related national traditional horse racing festival, actively guide the development of national traditional horse racing festival in the direction of tourism, actively guide the transformation of horse racing festivals, and promote the positive interactive development of Tibetan horse racing festivals and tourism. Make the Tibetan Horse Racing Festival a special sports tourism brand in Tibetan areas, and give play to the potential cultural, social and economic value of the deep integration of Tibetan Horse Racing Festival and tourism. In addition, the integration between the Tibetan Horse Racing Festival and tourism should be promoted from the following aspects: First, change the development concept and 
promote the development of the Tibetan Horse Racing Festival. It is necessary to take liberating thinking as a breakthrough to transform the Tibetan horse racing festival into an important content of cultural development in Tibetan areas. In particular, it is necessary to change the outdated concept of horse racing to catch horse racing, and strive to enhance market awareness, and expand through the important carrier and form of the Tibetan horse racing festival. The development of non-profit culture and business culture in Tibetan areas focuses on building a public sports and cultural service system in Tibetan areas and prospering the cultural market. Continue to build a cultural brand that represents Tibetan areas with Tibetan horse racing festivals, and strive to promote the comprehensive development of cultural undertakings in Tibetan areas. Second, promote the integration of tourism, culture, sports, economy and trade. The first is to use the unique tourism resources of each Tibetan area to fully demonstrate the Tibetan folk customs and culture with the regional characteristics of Tibetan areas, and to combine tourism, culture, and sports to create a grassland ecological sports tourism brand with characteristics of the Nagqu region. The second is to organize outstanding performances of relevant county folk art troupes to enrich tourists' travel itineraries in Tibetan areas. The third is to use the Tibetan Horse Racing Festival as a platform to increase investment attraction, formulate preferential policies that encourage enterprises to participate in the development of Tibetan horse racing tourism and farmers and herdsmen to participate in tourism reception services, and guide Tibetan farmers and herdsmen to use livestock products and handicrafts at the race meeting. During the period, he participated in the purchase and sale of material exchange meetings to promote the income of farmers and herdsmen and open up new paths for economic development in Tibetan areas.

\section{ACKNOWLEDGMENT}

Funding: This research is the staged result of the Tibetan National Horse Racing Festival brand building research (approval number: 19CTY004) under the "One Belt and One Road" initiative of the National Social Science Fund Youth Project in 2019.

\section{REFERENCES}

[1] Grah, Barbara; Dimovski, vlado; Peterlin, Judita (2020) Managing sustainable urban tourism development: the case of ljubljana. Sustainbility, 12(3): 792

[2] Vrtiprah, Vesna; Sesna; Sentic, Sanja (2018) Event in the function of better positioning of tourist destinations - the case study of dubrovnik. Ekonomska Misao I Praksa-Economic Thought and Practice, 27(1): 267-284

[3] Enang I A, Ajake A O, Amalu T E (2016) Volumetric analysis of tourist arrivals in ecotourism sites of Cross River state, Nigeria. Journal of Tourism and Management Research, 1(1): 135-154

[4] Li Xiang Ru (2020). The era characteristics and development trend of leisure sports in my country. Available at https://www.sohu.com/a/425582066_472516

[5] Miyake Masashi; Fujii Akira; Ohno Takashi; Yoshikawa Masateru (2018) Place-based services platform that enhances user satisfaction from sports tourism to daily life. Fujitsu Scientific and Technical Journal, 54(4): 38-43

[6] Amalu T E, Duluora E I, Otop O O, Omeje V U, Emeana S (2017) Assessment of tourists' patronage 
of Obudu mountain centres, Cross River state, Nigeria. Journal of Hospitality and Management Tourism, 8(4): 32-41

[7] Amalu T E, Ojugbo P A, Oqua O O (2018) Assessment of impact of recreational resorts on socioeconomic growth of Calabar, Cross River State, Nigeria. Sustainable Geoscience and Geotourism, 1(1): $11-24$

[8] Joanna Poczta, Agata Dąbrowska, Marek Kazimierczak, François Gravelle, Ewa Malchrowicz-Mośko (2020) Overtourism and Medium Scale Sporting Events Organisations - the Perception of Negative Externalities by Host Residents. Sustainability, 12(7): 110-121

[9] 감상호, 이재우, 최일문 (2019) Performance analysis of sport event: focused on the regional specialized sports tourism industry development project. 한국체육과학회지 28(3): 44-52

[10] Mihaela-Cornelia Dan (2019) Sustainable entrepreneurship in the Romanian sports industry. Proceedings of the International Conference on Business Excellence, 13(1): 1236-1245

[11] Mohammad Saeid Kiani, Leila Nazari, Leila Shahbazpour (2019). Sport Tourism and Sustainable Local Development for Host Cities for Sporting Events. American Journal of Sports Science, 7(1): 1522

[12] Ewa Malchrowicz-Mośko, Joanna Poczta (2018). A small-scale event and a big impact-is this relationship possible in the world of sport? the meaning of heritage sporting events for sustainable development of tourism--experiences from poland. Sustainability, 10(11): 115-126

[13] 김윤수, 윤광재 (2018). An empirical analysis of sports events on local economy. 한국정책과햑학호보, 22(2): $256-263$

[14] Zhang Zhao Jun, Jun Meng (2016). Research on the interactive development of traditional sports festivals and tourism. Journal of Ezhou University, 23(6): 92-94

[15] Liu Jin Bin (2014). A historical analysis of the Tibetan Horse Race in Kangding. Fighting (Sports Forum), 6(2): 83-86

[16] He Xi Yan (2015). Field investigation of Qinghai Yushu Jockey Club--A case study of "The 8th Kham Cultural Tourism Art Festival and Yushu Jockey Club". Journal of Nationality Normal College of Qinghai Normal University, 26(2): 7-13

[17] Li Yao (2020). A brief talk on the impact of the Horse Race in Dali Sanyue Street Ethnic Festival on the Local Economy. Sports Supplies and Technology, (10): 84-85

[18] Liang Min (2007). A preliminary study on the model of combining traditional festivals with tourism economy in ethnic minority areas--taking "August 1st" International Horse Racing Festival in Litang County as an example. Journal of Hubei University for Nationalities (Philosophy and Social Sciences Edition), (01): 37-41

[19] Zhou Gang (2015). Feasibility study on the development of horse racing industry in Gansu province. Sports Supplies and Technology, (08): 8-9

[20] Lv Wei, Bao Xiao Qiang (2019). A study on the current situation of Jockey Clubs in Hexi region of Gansu Province--Taking Sunan County as an example. Wushu Research, 4(5): 121-123

[21] He Zhang, Xi Chen, Miqi Li (2020). Investigation on the development status of Gannan Maqu "Gesar Jockey Club". Cultural and educational materials, (3): 97-99

[22] Rashidi, Mohsen; Hamzepour, Rezgar; Ismaelzadeh, Saleh (2018). Regional Planning Tourism Strategies Based on the SOAR Approach (Case Study: Marivan City). ASIAN Journal of Water Environment and Pollution, 15(2): 13-21 
[23] Cheng Ming Ming; Edwards, Deborah; Darcy, Simon (2018). A tri-method approach to a review of adventure tourism literature: bibliometric analysis, content analysis, and a quantitative systematic literature review. Journal of Hospitality \& Tourism Research, 42(6): 997-1020

[24] Marko Perić, Jelena Durkin, Vanja Vitezić (2018). Active event sport tourism experience: The role of the natural environment, safety and security in event business models. International Journal of Sustainable Development and Planning, 13(5): 758-772

[25] Mackellar Joanne; Nisbet Sharen (2017). Sport events and integrated destination development. CURRENT ISSUES IN TOURISM, 20(13): 1320-1335

[26] Krist Stefan (2019) Shamanic Sports: buryat wrestling, archery, and horse racing. Religions, 10(5): 306-318

[27] Toktabaev V (1996). Traditional horse training of the kasakhs. Pferdeheilkunde, 12(2): 129-132

[28] 김종국, 윤호중 (2017) Horse racing tourist and business priorities activated factors analysis: focused on utilizing AHP. 관광연구논총, 29(1): 115-125

[29] Philippe, Marion; Schut, Pierre-Olaf (2019) From the career to the leisure base: the tourist transformation of a marginal territory, the Ile-de-France example. Loisi \& Societe-Society and Leisure, 42(3): 487-502

[30] Hinch Lidija; Weismayer Christian (2018) Sustainable sport tourism in Japan. Tourism Planning \& Development, 15(1): 96-101

[31] National Bureau of Statistics of China (2020) 2018 national sports industry total scale and value added data announcement. Available at http://www.stats.gov.cn/tjsj/zxfb/202001/t20200120_1724122.html

[32] National Bureau of Statistics of China (2020) 2018 China's sports tourism market status and industry development trends. Available at https://www.sohu.com/a/332264780_505583

[33] National Bureau of Statistics of China (2020) The added value of national tourism and related industries in 2018 was 4,147.8 billion yuan. Available at http://finance.sina.com.cn/roll/2020-0119/doc-iihnzhha3471810.shtml

[34] National Bureau of Statistics of China (2020) Announcement on the total scale and added value of the national sports industry in 2019. Available at http://www.kssbzx.net.cn/zcfg/14231.html

[35] Wang, Yujuan; Wang, Mudi; Zhang, Jianxin; Li, Bing (2017). Development trend of sports tourism industry based on econometric model from the perspective of macroeconomics. Boletin Tecnico/Technical Bulletin, 55(16): 7-15

[36] Oğuz Taşpınar (2018) A new concept generated by commoditizing animals: egological tourism. Advances in Hospitality and Tourism Research, 6(1): 11-22

[37] Ajake A O, Amalu T E. (2012) The relevance of tourism on the economic development of Cross River state, Nigeria. Journal of Geography and Regional Planning, 5(1): 11-25

[38] Economics - Sports Economics (2020) New sports economics study findings reported from University of Zurich (team visibility and city travel: evidence from the Uefa champions' league random draw). Journal of Transportation, 35(4): 8-12

[39] Takon T, Amalu T E, Okpara, D. (2013) Assessment of local people's attitude towards natural resource conservation in Boki Local government area, Cross River state, Nigeria. Research Journal in Organizational Psychology and Education Studies, 2(2): 60-66

[40] Zhang J, Inbakaran R J, Jackson M S (2006) Understanding Community Attitudes towards Tourism and Host-Guest Interaction in the Urban-Rural Border Region. Tourism Geographies, 8(2): 182-204 
[41] 김주진 신우진 (2020) The impact of the physical connectivity among islands on the relationship between recognition of the impact of tourism development and residents' support: the case of Bogil island luxury fishing village in Wando-gun. 국토계획 55(2): 139-145

[42] Heetae Cho, Dongoh Joo, Kyle Maurice Woosnam (2020) Cross-cultural validation of the nostalgia scale for sport tourism (NSST): a multilevel approach. Journal of Hospitality \& Tourism Research, 44(4): 1369-1378

[43] Amalu T E, Ajake A O (2014) Influence of Calabar carnival on the economy of residents of Calabar metropolis, Cross River state, Nigeria. Global Journal, 1(1): 67-81

[44] 김재학, 감성조 (2020) Direction of regional tourism based on a mega sports event's legacies and issues: focusing on the post-Pyeongchang Winter Olympics. 관광연구저널 34(5): 48-62

[45] Pamela Wicker (2020) The impact of participation frequency and travel distances for different sport participation purposes on subjective well-being: the 'unhappy commuter' and the happy sport tourist?. European Sport Management Quarterly, 20(3): 117-128

[46] Cooper J A, Derek H. Alderman (2020) Cancelling March madness exposes opportunities for a more sustainable sports tourism economy. Tourism Geographies, 22(3): 1189-1198 